\title{
Construction and progress of Chinese terrestrial ecosystem carbon, nitrogen and water fluxes coordinated observation
}

\author{
YU Guirui ${ }^{1}$, REN Wei ${ }^{1,2}$, CHEN Zhi ${ }^{1}$, ZHANG Leiming ${ }^{1}$, WANG Qiufeng ${ }^{1}$, \\ WEN Xuefa ${ }^{1}$, HE Nianpeng ${ }^{1}$, ZHANG Li ${ }^{1}$, FANG Huajun ${ }^{1}$, ZHU Xianjin ${ }^{1}$, \\ GAO Yang ${ }^{1}$, SUN Xiaomin ${ }^{1}$ \\ 1. Key Laboratory of Ecosystem Network Observation and Modeling, Institute of Geographic Sciences and \\ Natural Resources Research, CAS, Beijing 100101, China; \\ 2. University of Chinese Academy of Sciences, Beijing 100049, China
}

\begin{abstract}
Eddy Covariance technique (EC) achieves the direct measurement on ecosystem carbon, nitrogen and water fluxes, and it provides scientific data for accurately assessing ecosystem functions in mitigating global climate change. This paper briefly reviewed the construction and development of Chinese terrestrial ecosystem flux observation and research network (ChinaFLUX), and systematically introduced the design principle and technology of the terrestrial ecosystem carbon, nitrogen and water fluxes coordinated observation system of ChinaFLUX. In addition, this paper summarized the main progress of ChinaFLUX in the ecosystem carbon, nitrogen and water exchange and environmental controlling mechanisms, the spatial pattern of carbon, nitrogen and water fluxes and biogeographical mechanisms, and the regional terrestrial ecosystem carbon budget assessment. Finally, the prospects and emphases of the terrestrial ecosystem carbon, nitrogen and water fluxes coordinated observation of ChinaFLUX are put forward to provide theoretical references for the development of flux observation and research in China.
\end{abstract}

Keywords: eddy covariance technique; carbon-water-nitrogen fluxes; coupling cycle; coordinated observation; ChinaFLUX

\section{Introduction}

Accurately assessing the global, regional and national terrestrial ecosystem carbon budget and carbon exchange is an important theme in the global climate change researches. The assessment underlies the scientific basis to support the international joint actions to mitigate and adapt to climate change in the "United Nations Framework Convention on Climate Change (UNFCCC)” (Le Quéré et al., 2013). In recent decades, China's economy experi-

Received: 2016-01-04 Accepted: 2016-03-15

Foundation: Science and Technology Service Network Initiative of CAS, No.KFJ-SW-STS-169; National Natural Science Foundation of China, No.31420103917

Author: Yu Guirui, Professor, specialized in ecosystem ecology and global change science research. E-mail: yugr@igsnrr.ac.cn 
ences rapid development. The amount and growth rate of greenhouse gas emissions of China already leaped to the first in the world (Liu et al., 2015). Therefore, China faces enormous challenges in reducing the greenhouse gas emission and effectively governing the atmospheric pollution.

Greenhouse gases in the atmosphere mainly consist of $\mathrm{CO}_{2}, \mathrm{H}_{2} \mathrm{O}, \mathrm{CH}_{4}, \mathrm{NO}, \mathrm{NO}_{2}, \mathrm{~N}_{2} \mathrm{O}$, $\mathrm{NH}_{3}, \mathrm{HNO}_{3}$ and other trace gases. The greenhouse gas exchange between the ecosystem and the atmosphere are all closely related to the ecosystem carbon, nitrogen and water cycles. Coordinated observation on carbon, nitrogen and water fluxes between ecosystem and the atmosphere is an important approach to evaluate the terrestrial ecosystem functions of greenhouse gas absorption and digestion (Yu et al., 2014a). Also, terrestrial ecosystem carbon, nitrogen and water cycle processes and their coupling relations are the core processes in the global-scale biogeochemical cycles to determine the ecosystem services. Therefore, studies on terrestrial ecosystem carbon, nitrogen and water cycle processes and their coupling relations are the scientific foundation for understanding the interactions between ecosystem and global climate change, and are the frontiers in current geographical and ecological researches (Yu et al., 2013a, 2014b).

The development and application of flux observation technology, represented by the greenhouse gas $\left(\mathrm{CO}_{2}, \mathrm{H}_{2} \mathrm{O}\right.$ and $\left.\mathrm{CH}_{4}\right)$ eddy covariance techniques, could provide us the long-term continuous, high-frequency, multiple elements synchronous, and across sites networked ecosystem carbon, nitrogen and water fluxes and environmental elements data (Baldocchi, 2008, 2014; Yu et al., 2013a, 2014b). In the past two decades, the ecosystem $\mathrm{CO}_{2}$ and $\mathrm{H}_{2} \mathrm{O}$ flux observation have been carried out worldwide, and accumulated large amount of scientific data (Luysseart et al., 2007; Reichstein et al., 2014; Baldocchi et al., 2008, 2014; Yu et al., 2013b). Recently, continuous observation of $\mathrm{CH}_{4}, \mathrm{NO}, \mathrm{NO}_{2}, \mathrm{~N}_{2} \mathrm{O}$, $\mathrm{NH}_{3}, \mathrm{HNO}_{3}$ and other carbon, nitrogen and water trace gas fluxes is gradually applied in the field (Baldocchi, 2014). These data lay the solid foundation for assessing the carbon, nitrogen and water and trace gas budget, exploring the controlling mechanism for carbon, nitrogen and water fluxes and their coupling relations, and predicting the responses and adaption of carbon, nitrogen and water cycle processes to global climate change (Yu et al., 2014b).

The Chinese terrestrial ecosystem flux observation and research network (ChinaFLUX) was established in 2001. Continuous measurement of $\mathrm{CO}_{2}, \mathrm{H}_{2} \mathrm{O}$ and energy fluxes, synchronous environmental elements, and ecosystem properties were started since 2002 (Yu et al., 2006a, b; Yu and Sun, 2006). ChinaFLUX has made great progress in the original data accumulation, mechanism of ecosystem carbon, water cycle process, the model system development, and the regional carbon, water budget quantitative evaluation (Yu et al., 2014a). It promotes the development of flux researches in China and bridges the gaps in global flux observation thus gains worldwide appreciation (Leuning and $\mathrm{Yu}, 2006$; Doherty et al., 2009; Saigusa et al., 2013; Stoy et al., 2013). Recently, ChinaFLUX takes the lead to develop the terrestrial ecosystem carbon, nitrogen and water fluxes coordinated observation system, promote the observation and field control experiment network researches on ecosystem carbon, nitrogen and water coupling cycles and their responses to climate change, and expand the frontier research field in the terrestrial ecosystem and global change science (Yu et al., 2013a; Yu et al., 2014a, 2014b).

Based on the previous introduction of ChinaFLUX and its theoretic framework of terres- 
trial ecosystem carbon, nitrogen and water coupling cycle researches ( $\mathrm{Yu}$ et al., 2006b, 2013a, 2014a, 2014b), this study briefly reviewed the construction and development history of ChinaFLUX, and mainly systematically summarized the main progress of ChinaFLUX in the key technology exploration and application of the carbon, nitrogen and water fluxes coordinated observation system, and progress in the studies on the ecosystem carbon, nitrogen and water exchange and environmental controlling mechanisms, the spatial pattern of carbon, nitrogen and water fluxes and biogeographical mechanisms, and regional terrestrial ecosystem carbon budget assessment. Finally, the future development strategies of ChinaFLUX coordinated observation system on terrestrial ecosystem carbon, nitrogen and water fluxes are proposed so as to provide theoretical references for the development of flux observation and research in China.

\section{Construction of the ChinaFLUX coordinated observation on terrestrial ecosystem carbon, nitrogen and water fluxes}

\subsection{Establishment and development of ChinaFLUX}

Supported by the Knowledge Innovation Program of the Chinese Academy of Sciences "Study on Carbon Budget in Terrestrial and Marginal Sea Ecosystems of China", the Chinese Terrestrial Ecosystem Flux Observation and Research Network (ChinaFLUX) was launched in 2001. By one year's well-design on the observation system, instrument selection and site investigation, the first 8 stations (4 forests, 3 grasslands and 1 cropland) and 1 integrated research center of ChinaFLUX were established in 2002. Since then, the long-term coordinated flux measurement is started formally in China (Yu et al., 2006a, 2006b; Yu and Sun, 2006).

ChinaFLUX was subsequently supported by a series of programs. Such projects promote the development of ChinaFLUX through the increase of flux sites, extension of spatial representativeness and improvement of observation capability. ChinaFLUX gradually become a unique scientific and technological platform for carbon cycle and global change in China (Yu et al., 2014a). ChinaFLUX also promotes its international development, with great achievement in prompting the recombination of Asian flux network (AsiaFlux). Currently, ChinaFLUX becomes not only a distinctive observation and research network in Chinese Ecosystem Research Network (CERN), but also an important component of the Asian and global flux network (FLUXNET).

The development of ChinaFLUX takes the lead in the construction of flux stations from forestry, agricultural, meteorological departments and some universities, and also provides the important basis for coordinated flux measurement and resources integration among different departments in China. In 2014, the Chinese Flux Observation and Research League (new ChinaFLUX) was formed through the combination between ChinaFLUX and other flux stations from different departments. Currently, there are 71 flux stations in ChinaFLUX, which includes 22 forests, 17 grasslands (deserts), 17 croplands, 13 wetlands, 1 urban and 1 lake sub-network. The sites cover tropical, temperate and boreal typical climate zones in China (Figure 1). The national scale ecosystem flux observation and research network has been preliminarily established. 


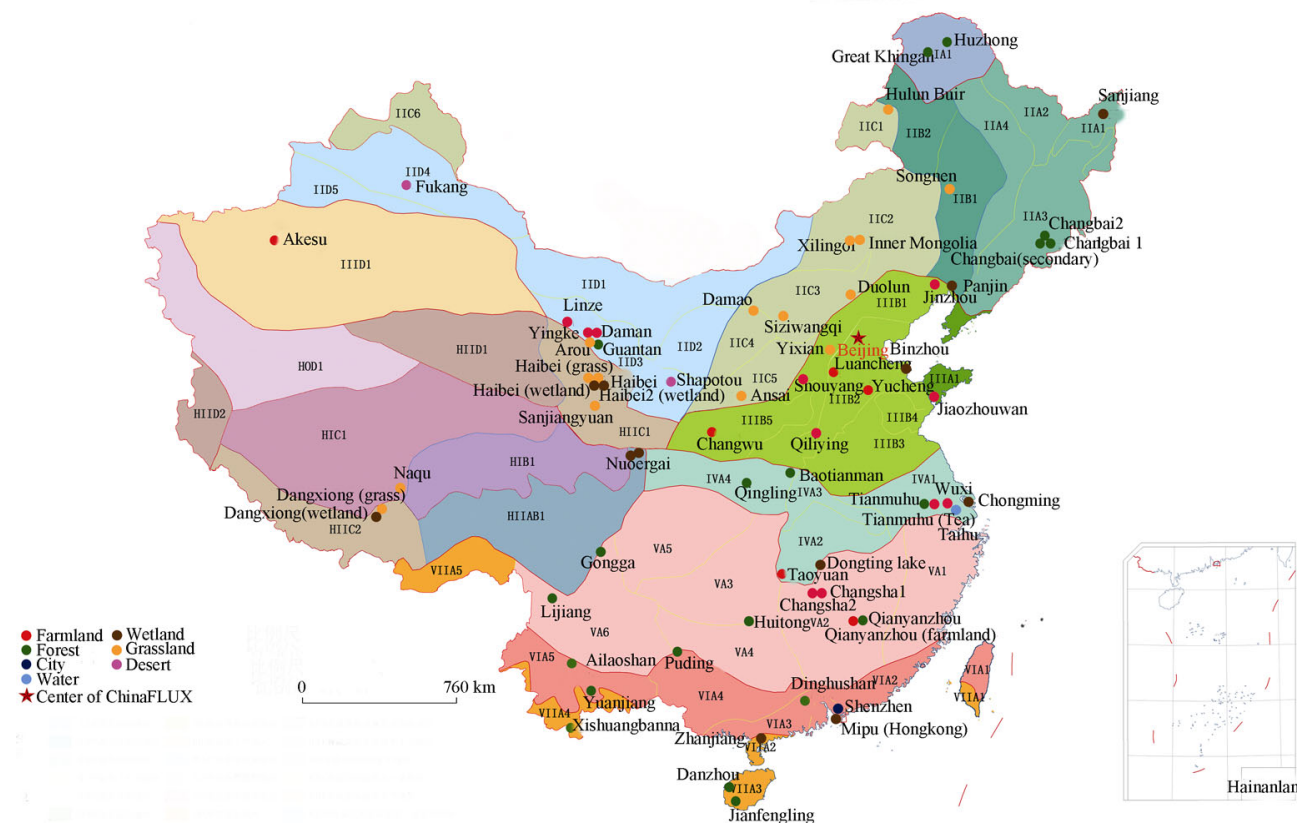

Figure 1 Site distribution of ChinaFLUX

\subsection{Design of the coordinated observation on terrestrial ecosystem carbon, nitrogen and water fluxes of ChinaFLUX}

The scientific targets of ChinaFLUX is designed to (1) establish the national ecosystem observation and research platform; (2) accumulate the long-term scientific data of carbon, nitrogen and water fluxes, meteorological, biotic and soil factors, and ecosystem elements; (3) organize the mechanism researches on carbon, nitrogen and water coupling cycle processes and environmental regulation across ecosystem, transect, regional and global scales; (4) provide scientific support for dealing with climate change and promoting the sustainable development of environment and society (Figure 2) (Yu et al., 2014a).

With over decadal development, the scientific researches of ChinaFLUX has been evolved from the traditional $\mathrm{CO}_{2}, \mathrm{H}_{2} \mathrm{O}$ fluxes and their dynamic (daily, seasonal, annual) and spatial (regional, national, continental, global) variations, to the coupling cycles of carbon, nitrogen, and water fluxes and controlling mechanisms (physical, chemical, biological) (Figure 2). The observation techniques of ChinaFLUX also developed from the traditional carbon and water flux eddy covariance technology, to the coordinated system of nitrogen deposition observation, carbon and water stable isotopic synchronous observation, $\mathrm{CH}_{4}, \mathrm{~N}_{2} \mathrm{O}$ and other greenhouse gas observation and hydrological processes observations.

The observational technology development largely prompts the capability of ChinaFLUX in the typical terrestrial ecosystem carbon, nitrogen and water flux coordinated observation, national scale carbon and nitrogen flux network observation, and adaptation of ecosystem carbon, nitrogen and water cycle to global change field control experimental researches. ChinaFLUX proposed the development strategy to construct the coordinated observation on terrestrial ecosystem carbon, nitrogen and water fluxes in China. 

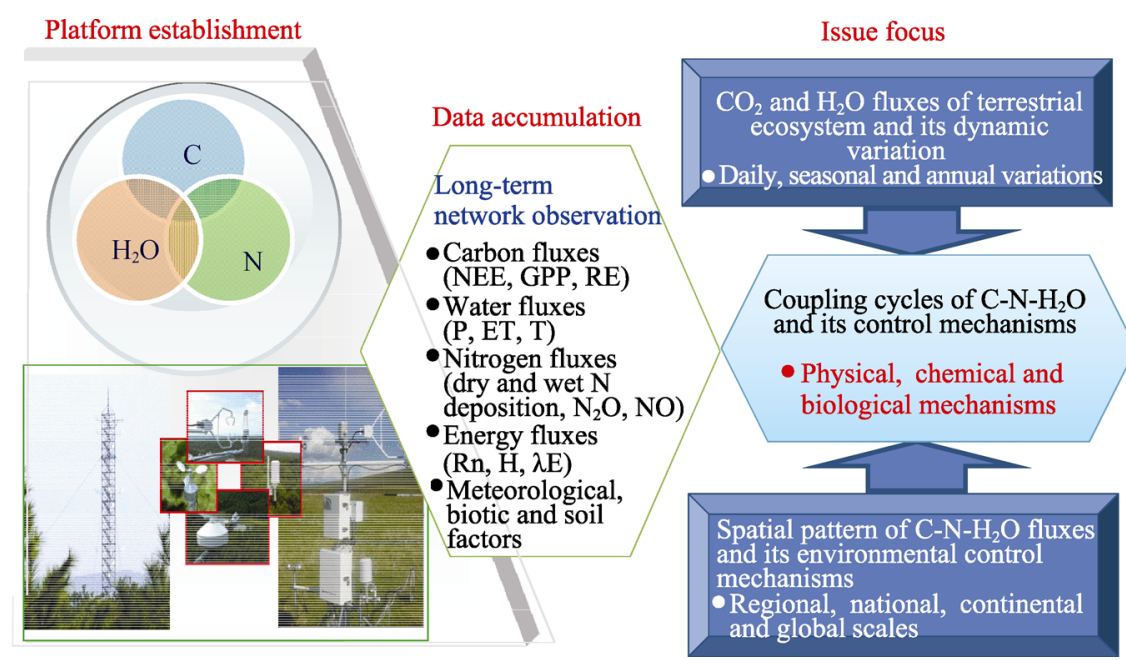

Science support

Deal with global change

- Assess C-N-H $\mathrm{H}_{2} \mathrm{O}$ budget

- Increase C sink

- Mitigate global change

- Adapt to global change

Support sustainable development

- Monitor ecological change

- Evaluate ecological services

- Manage ecosystems

- Protect

environment

Figure 2 Scientific targets of ChinaFLUX

\subsection{Main scientific issues in the coordinated observation on ecosystem carbon, nitro- gen and water fluxes of ChinaFLUX}

Research on the ecosystem carbon, nitrogen and water cycles and their coupling relationships is the scientific requirement for regulating and managing ecosystem processes to mitigate global change. The key mission of ecosystem carbon, nitrogen, and water fluxes researches of ChinaFLUX is to cognize the ecosystem carbon, nitrogen and water cycle processes and its environmental controlling mechanism, multi-scale temporal variation of carbon, nitrogen, water fluxes and its dynamic mechanism, and ecosystem carbon, nitrogen, water coupling cycles response to global change and its adaptive mechanisms. Specifically, ChinaFLUX mainly focuses on four scientific issues (Figure 3): (1) the key processes and its biological controls of the ecosystem carbon, nitrogen and water coupling cycles; (2) the stoichiometric equilibrium and its environmental responses of ecosystem carbon, nitrogen and water fluxes; (3) the regulation mechanism of the ecosystem carbon, nitrogen and water coupling cycles on the spatio-temporal pattern of terrestrial ecosystem carbon sink/source; (4) the response and adaptation of the biological processes of ecosystem carbon, nitrogen and water coupling cycles to global change (Yu et al., 2014b).

\section{Construction and key technology of the coordinated observation on eco- system carbon, nitrogen and water fluxes of ChinaFLUX}

\subsection{Design of carbon, nitrogen and water multi-elements coordinated observation system in typical ecosystems}

The systematic design of ChinaFLUX persists in combining long-term continuous instrumental observations and control experiments as guideline. It emphasizes the synthetic observation of multiple greenhouse gas fluxes, environmental elements and ecological processes, as well as the coordinated observation of carbon-nitrogen-water fluxes and cycle processes. ChinaFLUX focuses on the development of the continuous and in situ carbon and 


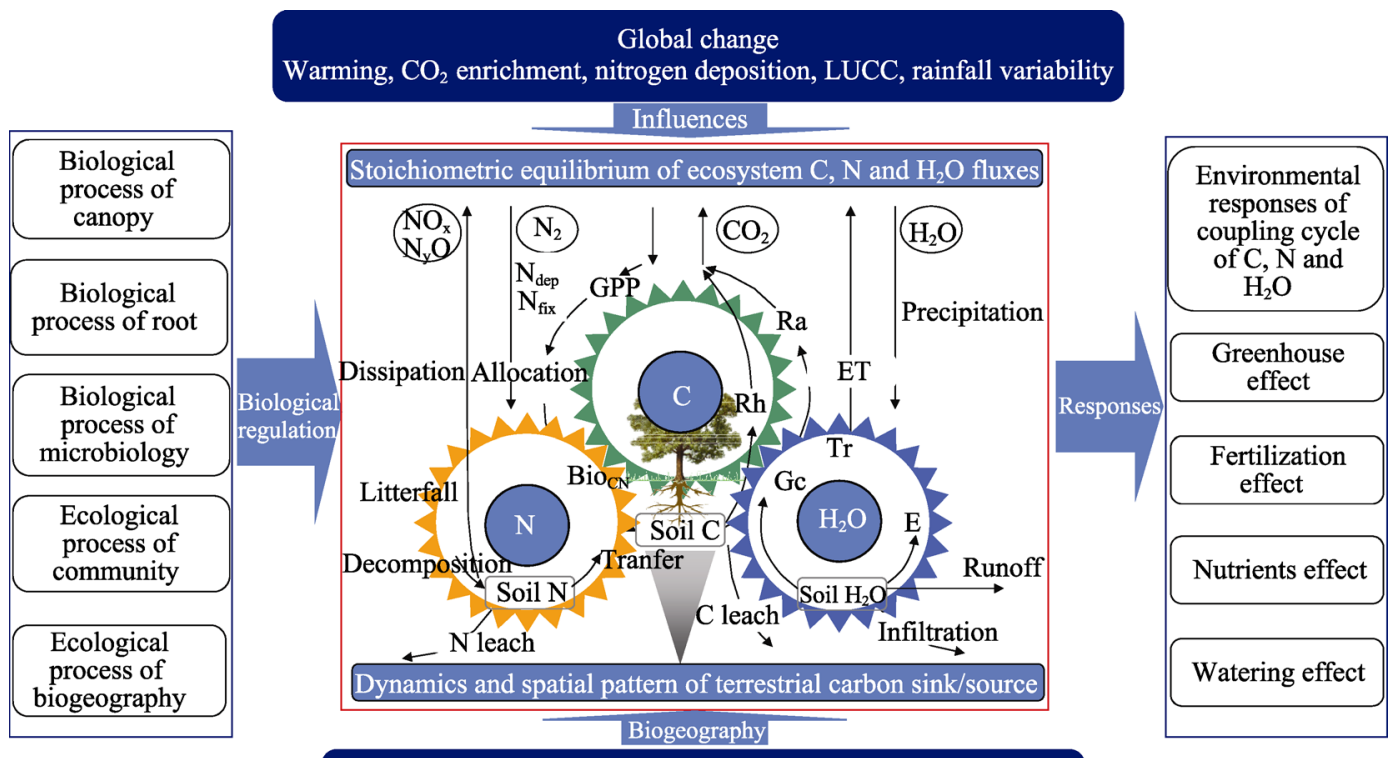

Dynamics and spatial pattern of soil, vegetation, meteorology and climate environmental variations

Figure 3 Scientific issues of the coordinated observation on ecosystem carbon, nitrogen and water fluxes of ChinaFLUX

C: Carbon; N: Nitrogen; GPP: Gross primary production; Ra: Autotrophic respiration; Rh: Heterotrophic respiration; ET: Ecosystem evaportranspiration; Tr: Transpiration; E: Evaporation; LUCC: Land use cover change

water stable isotope fluxes observational techniques, soil $\mathrm{CO}_{2}, \mathrm{CH}_{4}$ and $\mathrm{N}_{2} \mathrm{O}$ fluxes coordinated observational technique, and the atmospheric deposition flux observation and $\mathrm{N}$ tracer technique. By systematically integration of ecological, meteorological and isotopic techniques, ChinaFLUX prospectively built the carbon, nitrogen and water multi-elements coordinated observation system in typical ecosystems (Figure 4) (Yu et al., 2014a).

The development of in situ ecosystem carbon and water stable isotope fluxes measurement technique overcame the problem of nonlinear response of instruments (Wen et al., $2008,2012)$. It allowed in situ and continuous measurement of $\delta^{18} \mathrm{O}$ and $\delta \mathrm{D}$ of atmospheric water vapor (Wen et al., 2010; Zhang et al., 2011; Huang et al., 2014), and isotopic ratio and flux ratio of atmospheric $\mathrm{CO}_{2} \delta^{13} \mathrm{C}$ (Pang et al., 2016). This technology broke through the bottleneck of coordinated observation of eddy covariance and stable isotopes. It achieves the coordinated observation of ecosystem carbon and water vapor flux and $\delta^{18} \mathrm{O}, \delta \mathrm{D}$ and $\delta^{13} \mathrm{C}$ fluxes (Wen et al., 2012, 2015).

Based on the theory of close path non-steady state measurement, the "automatic multi-channels soil $\mathrm{CO}_{2}, \mathrm{CH}_{4}$ and $\mathrm{N}_{2} \mathrm{O}$ flux coordinated observation device" was developed. This device adopted parallel connection to optimize the pressure fluctuation and reduce the system leakage based on a composite technology of near infrared and mid-infrared laser. Meanwhile, the pressure balance and gas mixing efficiency were improved. It could measure $\mathrm{CO}_{2}, \mathrm{CH}_{4}$ and $\mathrm{N}_{2} \mathrm{O}$ fluxes simultaneously, and collect data in the field automatically. The device increased the spatio-temporal representativeness of observational data and is useful for the synthesis of synchronous $\mathrm{CO}_{2}, \mathrm{CH}_{4}$ and $\mathrm{N}_{2} \mathrm{O}$ fluxes.

Atmospheric nitrogen deposition observation and nitrogen stable isotope tracing technol- 
ogy are useful technologies for ecosystem nitrogen cycle researches. In the coordinated observation system of ChinaFLUX, the technical specifications for atmospheric wet nitrogen deposition observation were compiled (Sheng et al., 2010; Zhan et al., 2014; Zhu et al., 2015). These specifications provided a series of uniform operate procedures, including monitoring equipment setup, samples collection and data analysis. Now, these specifications have been used by many scientists in specific sites or regions (Sheng et al., 2010; Zhan et al., 2014; Zhu et al., 2015). It improves the normalization of atmospheric wet nitrogen deposition in China to a large extent (Jia et al., 2014; Zhu et al., 2015). The application of stable nitrogen isotopic tracer technology including the natural abundance of ${ }^{15} \mathrm{~N}$ and addition of ${ }^{15} \mathrm{~N}$ maker in the nitrogen cycle researches were also discussed (Sheng et al., 2012, 2014; Xu et al., 2014; Zhan et al., 2014, 2015; Zhu et al., 2015). Additionally, to improve the method of static chambers and gas chromatography for soil $\mathrm{N}_{2} \mathrm{O}$ emission measurement, scientists of ChinaFLUX conducted systematic comparative experiments in aspects of static chambers construction, sampling plots setup, sampling frequency, and instruments (Zheng et al., 2008). Nowadays, the findings have formed a series of operational procedure and been widely used by many scientists (Zheng et al., 2008; Fang et al., 2014a, 2014b; Wang et al., 2015).

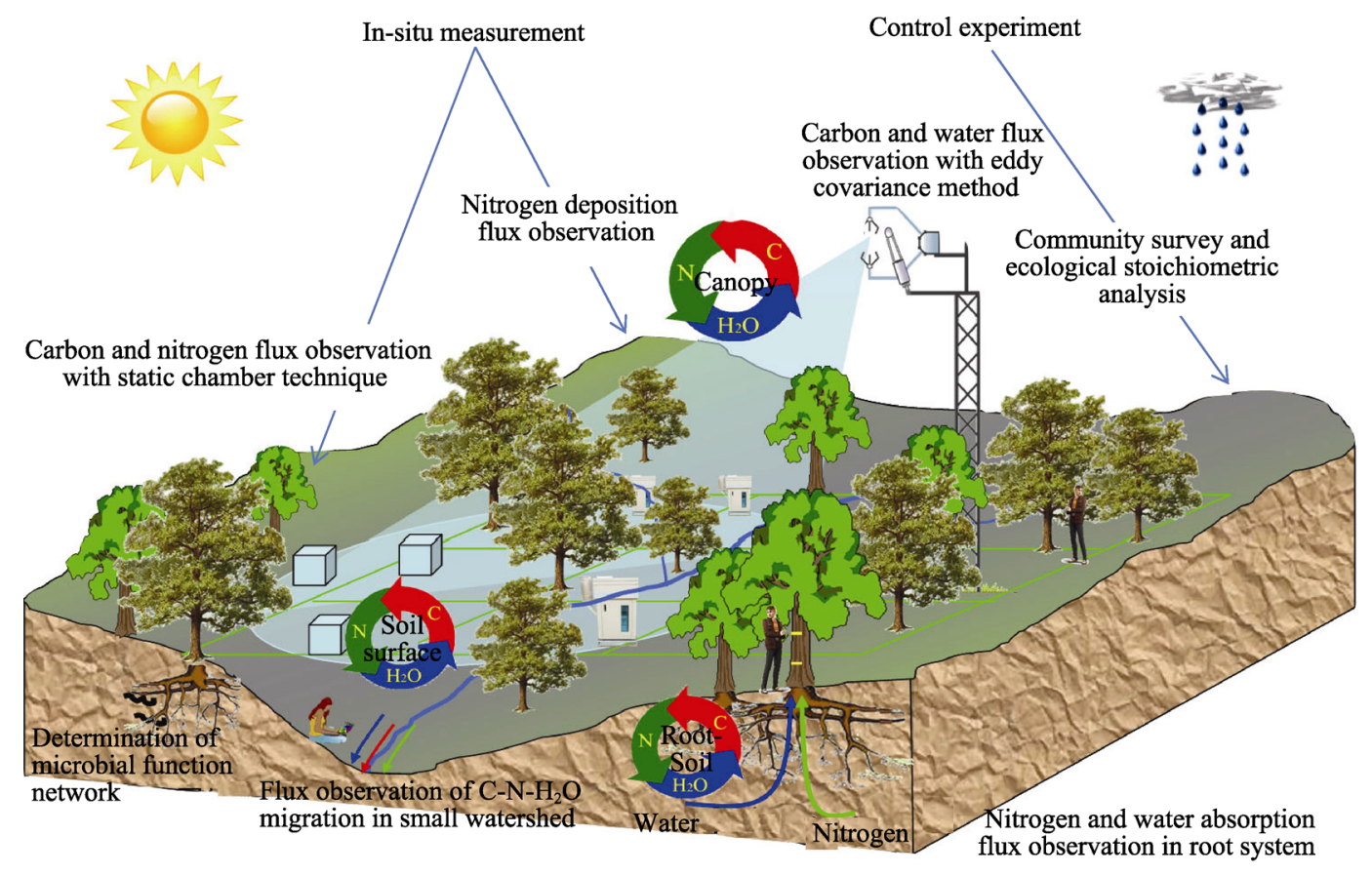

Figure 4 The carbon, nitrogen and water multi-elements coordinated observation system in typical ecosystems

\subsection{Design of multi-scale carbon, nitrogen and water coordinated observation system}

ChinaFLUX consistently emphasizes optimizing the spatial distribution of experiment sites. It follows the scientific principles of the geographic heterogeneity of ecosystem patterns, the diversity of ecosystem types at regional scale, and the representativeness in critical zones. By adopting the integrated and optimized approaches of the site-transect-region remote sensing observation, ChinaFLUX systematically designs the multi-scale carbon, nitrogen, 
water fluxes coordinated observation system. Along the transect, ChinaFLUX integrate science and technology resources of flux measurements, control experiments and transect researches to promote the build up and development of flux observation and experimental research network platform which underlies the foundation of super flux observational sites.

\subsection{The development of ecosystem carbon, nitrogen and water models and model- data fusion system}

Process-based ecosystem models and remote sensing models are important tools to estimate and predict dynamics variations and spatial patterns of ecosystem carbon, nitrogen, and water fluxes. ChinaFLUX community modified several process-based models and remote sensing models, such as CEVSA (Cao et al., 2005; Gu et al., 2010), In-TEC (Wang et al., 2007), EALCO (Mi et al., 2007; Mi et al., 2009), and BEPS (Wang et al., 2005; Ju et al., 2010), and VPM (Li et al., 2007; Wu et al., 2008). Meanwhile, many new models have been developed including AVIM2 (Ji et al., 2008; Huang et al., 2014), CEVSA2 (Gu et al., 2010; $\mathrm{Gu}$ et al., 2015), the evapo-transpiration model (Hu et al., 2013; Ren et al., 2005), a MODIS-based Photosynthetic Capacity Model (Gao et al., 2014), a remote sensing model for respiration ReRSM (Gao et al., 2015), and the statistical model GSM (Zheng et al., 2009; Yu et al., 2010; Zhu et al., 2014a).

In addition, a Model-Data Fusion System (MDFS) has been developed based on a series of algorithms including the Markov-Chain Monte Carlo method, the Monte Carlo Simulated Annealing method, and the sobol' method (Zhang et al., 2009, 2010; Ren et al., 2012) to quantify and minimize the model uncertainty. This system has been used for the uncertainty estimation for eddy flux measurements (He et al., 2010; Liu et al., 2009), model parameter estimation and carbon fluxes simulation and uncertainty estimation at site (Zhang et al., 2010; Liu et al., 2012, 2015) and regional scales (He et al., 2014), which provides an effective solution for scaling from site to regional levels and a platform for assessing the carbon and water balances on the national scale.

\section{Spatio-temporal patterns of terrestrial ecosystem carbon, nitrogen and water fluxes and environmental control mechanisms}

By more than 10-year's network observation, ChinaFLUX accumulates the valuable and unique data of ecosystem carbon, nitrogen and water fluxes in China. ChinaFLUX conducted a series of studies and gained great progress in the aspects of ecosystem carbon, nitrogen and water exchange dynamics and environmental controlling mechanisms, the spatial pattern of carbon, nitrogen and water fluxes and biogeographical mechanisms, and the regional terrestrial ecosystem carbon budget assessment.

\subsection{Evaluation of ecosystem carbon sink/source based on flux measurement}

The carbon sink/source of ecosystem in typical climate zones were investigated (Table 1). Forests were found to have a strong carbon sequestration capacity. The highest carbon sink appeared in central subtropical forests $\left(550 \pm 258 \mathrm{~g} \mathrm{C} \mathrm{m}^{-2} \mathrm{yr}^{-1}\right)$, and followed by warm temperate forests $\left(492 \pm 37 \mathrm{~g} \mathrm{C} \mathrm{m}^{-2} \mathrm{yr}^{-1}\right)$ and northern subtropical forests $\left(343 \mathrm{~g} \mathrm{C} \mathrm{m}^{-2} \mathrm{yr}^{-1}\right)$. Table 1 Statistics of carbon fluxes of ecosystems in typical climate zones of China (Mean \pm Standard deviation) 


\begin{tabular}{|c|c|c|c|c|c|c|}
\hline $\begin{array}{l}\text { Ecosys- } \\
\text { tem } \\
\text { types }\end{array}$ & Climate zones & $\begin{array}{c}\text { NEP } \\
\left(\mathrm{g} \mathrm{C} \mathrm{m}^{-2}\right. \\
\left.\mathrm{yr}^{-1}\right)\end{array}$ & $\begin{array}{c}\mathrm{GPP} \\
\left(\mathrm{g} \mathrm{C} \mathrm{m}^{-2}\right. \\
\left.\mathrm{yr}^{-1}\right)\end{array}$ & $\begin{array}{c}\mathrm{RE} \\
\left(\mathrm{g} \mathrm{C} \mathrm{m}^{-2}\right. \\
\left.\mathrm{yr}^{-1}\right)\end{array}$ & Flux sites & References \\
\hline \multirow{7}{*}{ Forest } & Tropical & $202 \pm 47$ & $2156 \pm 263$ & $1954 \pm 310$ & XSBN, JFL & $\begin{array}{l}\text { Zhang et al.,2010; Chen et } \\
\text { al., } 2010\end{array}$ \\
\hline & $\begin{array}{l}\text { Southern sub- } \\
\text { tropical }\end{array}$ & $250 \pm 206$ & $1424 \pm 81$ & $1174 \pm 287$ & DHS, DG & $\begin{array}{l}\text { Sun et al., 2012; Yu et al., } \\
\text { 2013b; Chen et al., } 2014\end{array}$ \\
\hline & $\begin{array}{l}\text { Central } \\
\text { subtropical }\end{array}$ & $550 \pm 258$ & $1801 \pm 167$ & $1253 \pm 226$ & $\begin{array}{l}\text { HT, AQ, } \\
\text { YY, QYZ, } \\
\text { ALS }\end{array}$ & $\begin{array}{l}\text { Yu et al., 2013; Chen et al., } \\
\text { 2014; Tan et al., 2011; } \\
\text { Zhang et al., 2010; Zhao et } \\
\text { al. 2011; Han et al. } 2008\end{array}$ \\
\hline & $\begin{array}{l}\text { Northern sub- } \\
\text { tropical }\end{array}$ & 343 & 1288 & 965 & $\mathrm{XP}$ & Geng et al., 2011 \\
\hline & Warm temperate & $492 \pm 37$ & $1379 \pm 103$ & $887 \pm 67$ & DX, XLD & $\begin{array}{l}\text { Huang et al., 2011; Zha et } \\
\text { al., 2007; Fang et al., } 2011\end{array}$ \\
\hline & Temperate & 302 & 1338 & 1036 & CBS & $\begin{array}{l}\text { Yu et al., 2013b; Chen et } \\
\text { al., } 2014\end{array}$ \\
\hline & Cool temperate & $135 \pm 114$ & $970 \pm 326$ & $774 \pm 298$ & $\mathrm{HZ}, \mathrm{LS}$ & $\begin{array}{l}\text { Wang et al., 2008; Cui et } \\
\text { al., 2007; Qiu et al., 2011; } \\
\text { Zhou et al., } 2010\end{array}$ \\
\hline \multirow[t]{2}{*}{$\begin{array}{l}\text { Grass- } \\
\text { land }\end{array}$} & Temperate & $24 \pm 83$ & $282 \pm 108$ & $260 \pm 95$ & $\begin{array}{l}\text { DL, NM, } \\
\text { CL, XLHT } \\
(1,2,3) \\
\text { KBQ, TY, } \\
\text { LP, FK }\end{array}$ & $\begin{array}{l}\text { Yu et al., 2013b; Chen et } \\
\text { al., 2014; FLUXNET, 2013; } \\
\text { Du et al., 2012; Wang et al., } \\
\text { 2008; Liu et al., 2011a, } \\
2011 \mathrm{~b} \text {; Dong et al., 2011a, } \\
2011 \mathrm{~b} \text {; Zhang et al., } 2007\end{array}$ \\
\hline & Alpine & $45 \pm 59$ & $470 \pm 193$ & $424 \pm 146$ & $\begin{array}{l}\text { DX, SJY, } \\
\text { HB }\end{array}$ & $\begin{array}{l}\text { Yu et al., 2013b; Chen et } \\
\text { al., 2014; Wu et al., 2010; } \\
\text { Wang et al., } 2012\end{array}$ \\
\hline \multirow{3}{*}{ Cropland } & Subtropical & 675 & 1598 & 923 & TY & Zhu et al., 2005 \\
\hline & Warm temperate & $462 \pm 136$ & $1792 \pm 64$ & $1329 \pm 72$ & WS, YC & $\begin{array}{l}\text { Yu et al., 2013b; Chen et } \\
\text { al., 2014; Lei et al., 2010a, } \\
2010 \mathrm{~b}\end{array}$ \\
\hline & $\begin{array}{l}\text { Temperate } \\
\text { semi-arid }\end{array}$ & 75 & 381 & 306 & DL & $\begin{array}{l}\text { Zhang et al., 2007; } \\
\text { FLUXNET, } 2013\end{array}$ \\
\hline \multirow{4}{*}{ Wetland } & Subtropical & $577 \pm 123$ & $1553 \pm 155$ & $977 \pm 133$ & $\operatorname{DT}(1,2,3)$ & $\begin{array}{l}\text { Guo et al., 2010; Yan et al., } \\
\text { 2009; FLUXNET } 2103\end{array}$ \\
\hline & Warm temperate & 65 & 1298 & 1233 & PJ & Zhou et al., 2009, 2010 \\
\hline & Cool temperate & $98 \pm 148$ & $570 \pm 116$ & $473 \pm 107$ & $\mathrm{SJ}(1,2,3)$ & Song et al., 2007 \\
\hline & alpine & -79 & 489 & 568 & HBSD & $\begin{array}{l}\text { Yu et al., 2013b; Chen et } \\
\text { al., } 2014\end{array}$ \\
\hline
\end{tabular}

Cool temperate forests showed lower carbon sink compared to warm temperate and temperate forests. Studies of specific ecosystem suggest that mature forests in Northeast, Southeast, and Southwest (Zhang et al., 2006a; Yu et al., 2008, 2013; Liu et al., 2014a; Tan et al., 2010, 2012; Guan et al., 2006; Zhang et al., 2006b; Yan et al., 2012) and subtropical plantations (Liu et al., 2006; Wen et al., 2010) had strong carbon sequestration capacity.

The carbon sink magnitude of grasslands was obviously lower than that of forests. Temperate steppes and alpine meadows served as weak carbon sink $\left(24 \pm 83,45 \pm 59 \mathrm{~g} \mathrm{C} \mathrm{m}^{-2} \mathrm{yr}^{-1}\right)$. The grasslands in northern China probably served as a weak carbon source after disturbances, which differed substantially among ecosystems and years (Shi et al., 2006; Zhao et al., 2006; Li et al., 2006; Wang et al., 2011; Fu et al., 2006, 2009; Yu et al., 2013b).

The magnitude of carbon sink differed substantially in croplands and wetlands. Croplands in temperate semi-arid zones $\left(75 \mathrm{~g} \mathrm{C} \mathrm{m}^{-2} \mathrm{yr}^{-1}\right)$ showed a much lower carbon sink than crop- 
lands in other climate zones $\left(675,462 \pm 136 \mathrm{~g} \mathrm{C} \mathrm{m}^{-2} \mathrm{yr}^{-1}\right)$. The subtropical coastal wetland had a high net carbon uptake capacity.

\subsection{Dynamics and environmental controlling on ecosystem $\mathrm{CO}_{2}$ flux}

\subsubsection{Dynamics of ecosystem $\mathrm{CO}_{2}$ flux across zonal vegetation}

Based on the long-term and continuous flux measurement, the diurnal, seasonal and interannual variations across different zonal vegetations were analyzed. (1) At daily scale, ecosystem $\mathrm{CO}_{2}$ flux was generally coherent with radiation and temperature which attained the peak at the middle of the day (Yu and Sun, 2006). (2) At seasonal scale, apparent unimodal variations of $\mathrm{CO}_{2}$ flux were presented for both mid- and high latitude and alpine vegetation in northern China and the Tibetan Plateau, while the differences among seasons were reduced in subtropical and tropical vegetation. Due to the limitation of soil moisture and low temperature, ecosystem $\mathrm{CO}_{2}$ flux of grassland in northern China and semi-arid region of the Tibetan Plateau presented high sensitivity to precipitation. For the cropland in northern China, bimodality pattern was appeared due to the crop rotation. (3) Due to the environmental changes, apparent interannual variability of $\mathrm{CO}_{2}$ flux was appeared in different ecosystems (Yan et al., 2013; Tan et al., 2012; Wen et al., 2010).

\subsubsection{Environmental responses of ecosystem $\mathrm{CO}_{2}$ flux}

From the synthesized analysis on ecosystem $\mathrm{CO}_{2}$ flux, the environmental responses of different terrestrial ecosystems in China were presented. For example, the effects of diffuse radiation (Fan et al., 2011; Zhang et al., 2009, 2010, 2011), water supply (Wen et al., 2006; Fu et al., 2006; Hao et al., 2010a; Wen et al., 2010; Wang et al., 2011), pulse rainfall (Hao et al., 2010b, 2011, 2013; Yan et al., 2011), and temporal distribution of precipitation (Yu et al., 2005; Yan et al., 2012, 2013) on ecosystem $\mathrm{CO}_{2}$ flux were elucidated. At the same time, a series of important ecological phenomena and their controling mechanism were illustrated. For example, the 'light depress' at ecosystem scale in temperate and alpine grasslands (Fu et al., 2006, 2009), the nonlinear response of ecosystem carbon flux to temperature variation (Yu and Sun, 2008), heterogeneous response of soil respiration to temperature (Tan et al., 2013; Jia et al., 2013; Song et al., 2013), the spatio-temporal variation of ecosystem light use efficiency (Yuan et al., 2010; Zhang et al., 2006c; Wu et al., 2008), and the 'carbon pool' in mountain area (Yao et al., 2012). Such studies enhance the understanding of the biotic and abiotic controlling mechanism of ecosystem $\mathrm{CO}_{2}$ flux across different temporal scales, and the response and adaptation of ecosystem flux to global change.

\subsection{The spatial pattern of ecosystem carbon fluxes and the underlying biogeographi- cal mechanisms}

\subsubsection{Global pattern of ecosystem carbon fluxes and biogeographical mechanisms}

Terrestrial ecosystems play an important role in regulating the atmospheric $\mathrm{CO}_{2}$ concentration and mitigating the global warming. However, the carbon exchange between terrestrial ecosystems and the atmosphere varies substantially at the spatial scale. To reduce the uncertainty of terrestrial ecosystems in the global carbon budget, it is necessary to understand the spatial variability of carbon flux and its controlling mechanism. ChinaFLUX researchers based on the ecosystem carbon flux data, quantitatively evaluated the spatial variability of 
ecosystem carbon flux in China (Yu et al., 2013b). GPP, RE and NEP showed obvious latitudinal pattern and mean annual temperature and precipitation and their interaction explained more than $60 \%$ of the spatial variation of GPP, RE and NEP in China (Yu et al., 2013b). Analyses of Asian, Northern Hemispheric and global carbon flux data all showed that the spatial variation of GPP, RE and NEP were mainly influenced by the pattern of mean annual temperature and precipitation (Yu et al., 2013b; Chen et al., 2013; Chen et al., 2015a). In the Northern Hemisphere, the pattern of mean annual temperature, precipitation and vegetation index NDVI jointly explained large parts of the spatial variation of GPP and RE respectively (Chen et al., 2015a). Further analysis revealed that the pattern of mean annual temperature and precipitation, through shaping the pattern of vegetation properties, to influence the spatial pattern of carbon fluxes (Chen et al., 2015a). Series of results provide evidence to the theory of climate pattern shaping the spatial pattern of ecosystem carbon fluxes at the regional and global scales. It reveals the underlying biogeographical mechanisms for the spatial pattern of carbon fluxes, and puts forward new approach to analyze and evaluate the regional and global ecosystem carbon budget from the aspect of the geographical distribution of climate factors (Yu et al., 2013b; Chen et al., 2013; Chen et al., 2015a).

\subsubsection{High carbon sinks and interrelations among carbon fluxes at spatial pattern}

Global analysis of carbon fluxes indicated that East Asian monsoon subtropical forests between $20^{\circ} \mathrm{N}$ and $40^{\circ} \mathrm{N}$ have high strength of carbon uptake and it attributes to the combined effects of the young stand ages, high nitrogen deposition and sufficient and synchronous water and heat availability (Yu et al., 2014c). Integrative analysis of global carbon fluxes data showed that GPP and RE co-varied at the spatial pattern from regional to global scale (Yu et al., 2013b; Chen et al., 2013; Chen et al., 2015b). The spatial pattern of GPP determined $90 \%$ of the global spatial pattern of RE and its underlying physiological mechanism due to the fact that production GPP functions as the direct substrate provider for respiration RE (Chen et al., 2015b).

\subsection{Dynamics of water vapor fluxes and water use efficiency and their environmental controlling mechanisms}

4.4.1 The spatio-temporal variations of ecosystem evapotranspiration and their influencing factors in China

Evapotranspiration (ET) is an important component of water cycle and energy balance in terrestrial ecosystems (Wang and Dickinson, 2012). Investigating the spatio-temporal variations of ET and their influencing factors is of great significance for water resource management and assessment (Zheng et al., 2016). Eddy covariance technique can directly measure water vapor fluxes between atmosphere and biosphere (Yu et al., 2006; Baldocchi, 2008), which plays an important role in exploring ET spatio-temporal variations and their affecting factors. Based on eddy covariance measured water vapor fluxes, ChinaFLUX investigated the diurnal variation (Li et al., 2010; Zheng et al., 2014), the seasonal dynamics (Tang et al., 2014; Zhou et al., 2010), and the interannual variation (Zhou et al., 2010; Xu et al., 2014) of ET in typical ecosystems. The results revealed the hysteresis responses of ET to air temperature and vapor pressure deficit in its diurnal variation (Zheng et al., 2014). The role of soil water content (Li et al., 2010; Tang et al., 2014) and air condition (Li et al., 2010; Zhou 
et al., 2010) in the seasonal dynamics of ET and the relative contributions of ecological responses and climate variation in ET interannual varitions (Zhou et al., 2010; Xu et al., 2014) were also clarified. In addition, based on measured ET, ChinaFLUX also revised the Shuttleworth-Wallace model and applied it in forests and grasslands ( $\mathrm{Hu}$ et al., 2009; Hu et al., 2013; Zhu et al., 2015). ET components were also separated with hydrogen and oxygen isotope from isotope online observations, which provides a critical tool to reveal the variations of ET components (Hu et al., 2014).

Based on the mechanism analysis of ET dynamics in typical ecosystems, ChinaFLUX also explored network observations to reveal the statistics of ET in typical regions and revealed the spatial variation of ET, especially the relationships between ET and climate and vegetation spatial patterns. The results indicated that annual net radiation, annual precipitation and annual mean temperature shaped the spatial pattern of ET, which provides a basis for assessing the spatial distribution of ET (Zheng et al., 2016). Network measured ET was also used to optimize the ET remote sensing model and to assess the spatial distribution of ET in China (Li et al., 2014).

4.4.2 The spatio-temporal variations of ecosystem water use efficiency and their environmental and biological controlling mechanisms

Water use efficiency (WUE) is an important parameter reflecting the interaction between carbon and water cycles. Analyzing the spatio-temporal variations of WUE, which would benefit for rational utilization of regional water resources, would improve our understanding on carbon and water cycles in terrestrial ecosystems (Zhu et al., 2015). Eddy covariance technique, which simultaneously measures carbon and water fluxes, laid an important data basis for analyzing the variations of WUE. Using eddy covariance measured GPP and ET, ChinaFLUX analyzed the dynamic of WUE in typical forests (Yu et al., 2008), grasslands (Hu et al., 2008) and cropland (Zhao et al., 2007) and found the "coupling and decoupling" phenomena in the dynamics of carbon and water fluxes. Then the biological and environmental mechanisms underlying the WUE dynamics (Yu et al., 2008, Hu et al., 2008) and their difference among regions were clarified (Zhu et al., 2014).

In addition, based on network eddy covariance measurements, the spatial variations of WUE among forests ( $\mathrm{Yu}$ et al., 2008), grasslands (Hu et al., 2008), and ecosystems having different ecosystem types (Zhu et al., 2015) were investigated, which were found to be differed among ecosystem types. Annual mean air temperature and annual precipitation were found to be the dominant factors influencing the spatial variation of WUE among forests (Yu et al., 2008), but leaf area index (LAI) was found to determine the spatial variation of WUE among grasslands ( $\mathrm{Hu}$ et al., 2008). Further analysis firstly illustrated the close relationship between WUE and altitude among different ecosystem types and found the spatial variation of WUE can be comprehensively reflected by elevation and LAI (Zhu et al., 2015). Then the spatial distribution of WUE was obtained to analyze the water cost of carbon sequestration and the reasonable regions in afforestation. The water cost of carbon sequestration threshold for afforestation was found to be near 400-500 $\mathrm{mm}$ rainfall, which made the region on the west of the threshold having huge water limit risk in afforestation (Gao et al., 2014). 


\subsection{Spatio-temporal patterns of atmospheric inorganic $\mathrm{N}$ deposition}

4.5.1 Spatio-temporal patterns of atmospheric wet $\mathrm{N}$ deposition in China and the influencing factors

China has been considered as one of three regions with the highest atmospheric nitrogen (N) deposition in the world. Therefore, understanding the spatio-temporal patterns and factors of atmospheric $\mathrm{N}$ deposition is useful to evaluate its ecological effects on terrestrial ecosystems. Based on CERN and some other ecological observation sties, researchers established a national observation network to monitor atmospheric $\mathrm{N}$ deposition.

The network revealed the composition of the wet $\mathrm{N}$ deposition in China and highlighted the importance of total particular N (TPN) through precipitation event. It was estimated, on the basis of the measured data, that the atmospheric wet $\mathrm{N}$ deposition of total dissolved $\mathrm{N}$ (TDN), $\mathrm{NH}_{4}{ }^{+}-\mathrm{N}$, and $\mathrm{NO}_{3}{ }^{-}-\mathrm{N}$ were $13.69,7.25$, and $5.93 \mathrm{~kg} \mathrm{~N}^{-1} \mathrm{yr}^{-1}$, respectively. The ratio of $\mathrm{NH}_{4}{ }^{+} / \mathrm{NO}_{3}{ }^{-}$was 1.22 on average at national scale. Furthermore, the deposition of TPN was about $4.33 \mathrm{~kg} \mathrm{~N} \mathrm{ha}^{-1} \mathrm{yr}^{-1}$, accounting for $24 \%$ of TN through precipitation event; these findings confirmed the ideas that atmospheric wet $\mathrm{N}$ deposition was underestimated without including TPN (Sheng et al., 2012; Zhan et al., 2014; Zhu et al., 2015). Meanwhile, through analyzing the published monitoring data during 1980-2000, researchers found that atmospheric dissolved inorganic $\mathrm{N}$ deposition (DIN, including $\mathrm{NH}_{4}{ }^{+}-\mathrm{N}$ and $\mathrm{NO}_{3}{ }^{-}-\mathrm{N}$ ) increased by $25 \%$ from the 1990 s to 2000 s in China (Jia et al., 2014). Atmospheric wet $\mathrm{N}$ deposition was the highest over southern China and exhibited a decreasing gradient from southern to western and northern China. Precipitation, N fertilizer use, and energy consumption were significantly correlated with atmospheric wet $\mathrm{N}$ deposition (Zhu et al., 2015).

4.5.2 Spatio-temporal patterns of atmospheric dry $\mathrm{N}$ deposition in China and influencing factors

Dry $\mathrm{N}$ deposition is an important component of total atmospheric $\mathrm{N}$ deposition. However, how to assess accurately atmospheric dry $\mathrm{N}$ deposition at regional and global scales is a big challenge for scientists, and the results have high uncertainty. Based on the chemical transformations between airborne reactive $\mathrm{N}$, researchers developed new methods which can evaluate the spatial patterns and trends of dry deposition fluxes in 2005-2014 in China and globally from ground $\mathrm{N}$ concentrations and the Ozone Monitoring Instrument (OMI) $\mathrm{NO}_{2}$ columns. The results showed that the average of dry $\mathrm{N}$ deposition fluxes in China was about $7.78 \mathrm{~kg} \mathrm{~N} \mathrm{ha}^{-1} \mathrm{yr}^{-1}$, and the fluxes of $\mathrm{NO}_{2}, \mathrm{HNO}_{3}, \mathrm{NH}_{4}{ }^{+}, \mathrm{NO}_{3}{ }^{-}$, and $\mathrm{NH}_{3}$ were estimated to be $0.67,1.15,0.28,0.07$ and $5.61 \mathrm{~kg} \mathrm{~N} \mathrm{ha}^{-1} \mathrm{yr}^{-1}$, respectively (Jia et al., 2016). Furthermore, North China, East China, and Central China were subjected to higher dry deposition $\mathrm{N}$ fluxes in China, which accompanied with a significant increase at the rate of $1-2 \mathrm{~kg} \mathrm{~N} \mathrm{ha}{ }^{-1}$ $\mathrm{yr}^{-1}$ in the past decade (Jia et al., 2016). China was not only the country with high dry $\mathrm{N}$ deposition fluxes but also the country with the greatest increase in dry $\mathrm{N}$ deposition fluxes over the past decade, where was expected as the most hotspots of $\mathrm{N}$ deposition. Large $\mathrm{NO}_{\mathrm{x}}$ and $\mathrm{NH}_{3}$ emissions resulted in the ongoing high $\mathrm{N}$ deposition in this region (Jia et al., 2016).

4.5.3 Mechanisms responsible for effects of atmospheric $\mathrm{N}$ deposition on soil greenhouse gas fluxes in the forest and grasslands

Terrestrial soils are the source or sink of atmospheric $\mathrm{CO}_{2}, \mathrm{CH}_{4}$, and $\mathrm{N}_{2} \mathrm{O}$, and are suscepti- 
ble to exogenous nitrogen inputs such as atmospheric nitrogen deposition. This thereby influences the regional and global carbon budget in terrestrial ecosystems (Liu and Greaver, 2010). The responses of soil greenhouse gas fluxes to $\mathrm{N}$ addition depend on the initial status of terrestrial ecosystems as well as the type and dose of $\mathrm{N}$ addition (Fang et al., 2014a). Oxidized $\mathrm{NO}_{3}{ }^{-}$and reduced $\mathrm{NH}_{4}{ }^{+}$inputs contrastingly affect soil greenhouse gas exchange fluxes. The promotion or inhibition on soil greenhouse gas fluxes are stronger from $\mathrm{NH}_{4}{ }^{+}-\mathrm{N}$ fertilizer addition than from $\mathrm{NO}_{3}{ }^{-}-\mathrm{N}$ fertilizer addition (Jiang et al., 2010; Fang et al., 2012; Wang et al., 2014). Also, the responses of soil greenhouse gas fluxes to $\mathrm{N}$ addition dose exhibit a nonlinear curve. Low dose of $\mathrm{N}$ addition inhibits soil $\mathrm{CO}_{2}$ and $\mathrm{N}_{2} \mathrm{O}$ emissions, but promotes soil $\mathrm{CH}_{4}$ uptake, whereas high doses of $\mathrm{N}$ inputs have contrary effects. Overall, these contrasting responses depend on the different stage of $\mathrm{N}$ saturation in terrestrial ecosystems (Fang et al., 2012, 2014; Xu et al., 2014). Furthermore, the environmental mechanisms driving the responses of soil greenhouse gas fluxes in the northern and southern forests of China to $\mathrm{N}$ enrichment are contrasting. Southern forests are mainly regulated by soil $\mathrm{NO}_{3}{ }^{-}-\mathrm{N}$ content, while northern forests are controlled by the combination of soil water and $\mathrm{NO}_{3}{ }^{-}-\mathrm{N}$ contents ( $\mathrm{Li}$ et al., 2015). As far as microbial mechanisms are concerned, soil microbial communities in the northern forests use mainly high energy soil substrates, but those of subtropical forests equivalently use various soil substrates. The difference in microbial resource utilization tactics dominates the spatial pattern of soil heterotrophic respiration $(\mathrm{Rh})$, and the tradeoff between root autotrophic respiration $(\mathrm{Ra})$ and $\mathrm{Rh}$ responded contrastingly to $\mathrm{N}$ addition determines the interannual variability of responses at the site scale (Fang et al., 2014b; Wang et al., 2015). In addition, $\mathrm{N}$ addition increases soil ammonia-oxidizing archaea (AOA) abundance, and does not change soil ammonia oxidizing bacteria (AOB) activity. The negative and positive relationships between soil AOA abundance and $\mathrm{CH}_{4}$ uptake and between soil AOA abundance and soil $\mathrm{N}_{2} \mathrm{O}$ emissions are often observed, suggesting changes in soil ammonia-oxidizing bacteria community structure can well explain the fluctuation between soil $\mathrm{CH}_{4}$ uptake and $\mathrm{N}_{2} \mathrm{O}$ emission (Wang et al., 2016).

4.5.4 Riverine carbon and nitrogen transport fluxes in Chinese terrestrial ecosystem and its impact on carbon cycle in coastal ecosystem

Rivers closely link carbon, nitrogen, water exchange between terrestrial and oceanic ecosystem, so riverine carbon, nitrogen, water exported flux monitor significantly impact on $\mathrm{C}$ and $\mathrm{N}$ biogeochemical process and associated couple at horizontal scale (Gao et al., 2013). The annual discharge of runoff and sediment from river systems to ocean bodies in China reaches up to $1.49 \times 10^{12} \mathrm{~m}^{3}$ and $1.72 \times 10^{9} \mathrm{t}$, respectively, wherein the runoff discharged into the East China Sea is the highest, approximating to $1.2 \times 10^{9}$ t (MWR, 2011a, b). Based on integration analysis on runoff and $\mathrm{C}$ transport in main Chinese rivers, the annual $\mathrm{C}$ transport from the river systems to coastal ecosystem bodies in China is $64.35 \mathrm{TgC}$, wherein the Yangtze River, Yellow River, and Pearl River in China contribute $76.9 \%$ of the total C transport in China. The Yellow River and the Yangtze River transport 21.71 TgC and 16.3 $\mathrm{TgC}$ annually, accounting for $33.7 \%$ and $25.3 \%$ of the total annual $\mathrm{C}$ transport in China, respectively (Gao et al., 2015; Zhu et al., 2012).

Although many research reports on the effect of $\mathrm{N}$ on $\mathrm{C}$ cycle in coastal ecosystem (Doney et al., 2007), there are few reports on $\mathrm{C}$ and $\mathrm{N}$ transport flux from river-ocean scale and elucidating its $\mathrm{C}$ and $\mathrm{N}$ coupling relationship. Based on $\mathrm{C} / \mathrm{N}$ ratio in aquatic ecosystem, 
Gao et al. (2015) estimate the effect of $\mathrm{N}$ export on $\mathrm{C}$ cycle in aquatic ecosystem. The results showed that the main forms of $\mathrm{N}$ discharged into Chinese coastal waters was $\mathrm{NO}_{3}{ }^{-}$and annual net $\mathrm{N}$ export from Chinese rivers reaches $12-15 \times 10^{8} \mathrm{~kg} \mathrm{~N} \mathrm{yr}^{-1}$, which constitutes $80 \%$ of the total of nutrient discharged into Chinese coastal ecosystem. Further estimation demonstrated that $\mathrm{N}$ transport flux from Chinese terrestrial ecosystem may account for $11 \%$ of the inorganic $\mathrm{C}$ exchange in air-sea interface (Gao et al., 2015). In the future, as to carbon, nitrogen, water coupling cycle in Chinese terrestrial ecosystem, we should strengthen monitoring on carbon, nitrogen, water horizontal export flux and external $\mathrm{N}$ and $\mathrm{P}$ transport, which would be helpful to exactly estimate $\mathrm{C}$ budget in Chinese terrestrial ecosystem and elucidate the effect of river on carbon, nitrogen, water coupling cycle in terrestrial ecosystem.

\subsection{Spatial pattern of carbon budget in China's terrestrial ecosystems}

\subsubsection{Carbon budget in Chinese terrestrial ecosystems based on carbon cycle model}

The approaches of carbon cycle model, as an important tool in C cycle research, play a vital role in regional $\mathrm{C}$ budget assessment. Using the carbon flux data measured by eddy covariance, the $\mathrm{C}$ models involving the optimized parameters have been developed to assess the spatio-temporal patterns of different components of $\mathrm{C}$ budget in China. Our findings showed that annual GPP ranged from 4.42 $\mathrm{Pg} \mathrm{C} \mathrm{yr}^{-1}$ to $6.03 \mathrm{Pg} \mathrm{C} \mathrm{yr}^{-1}$ in China (Yu et al., 2013c), while the values of annual NPP were between 1.43 and $1.43 \mathrm{Pg} \mathrm{C} \mathrm{yr}^{-1}$, with an average of $2.83 \pm 0.83 \mathrm{Pg} \mathrm{C} \mathrm{yr}^{-1}$ (Gao et al., 2012). Annual NEP resulting from the models was approximately $0.18 \pm 0.18 \mathrm{Pg} \mathrm{C} \mathrm{yr}^{-1}$, which ranged from 0.063 to $0.57 \mathrm{Pg} \mathrm{C} \mathrm{yr}^{-1}$ ( $\mathrm{Yu}$ et al., 2013c).

4.6.2 Carbon budget in Chinese terrestrial ecosystems based on the field investigated data

Field-investigated data are very important to evaluate the $\mathrm{C}$ budget in terrestrial ecosystems. In the past years, we integrated the multi-resource data, including long-term monitoring data and publicly published data to find that the stocks of soil organic carbon (SOC) and soil inorganic carbon (SIC) in 0-100 cm soil layer were 93.9 and $61.2 \mathrm{Pg} \mathrm{C}$, respectively. It was estimated that vegetation $\mathrm{C}$ storage was about $14.9 \mathrm{Pg} \mathrm{C}$, including $7.8 \mathrm{Pg} \mathrm{C}$ in forest vegetation, 2.1 Pg C in grassland vegetation, 3.4 Pg C in shrub vegetation, $0.95 \mathrm{Pg} \mathrm{C}$ in farmland vegetation, $0.49 \mathrm{Pg} \mathrm{C}$ in desert vegetation, and $0.25 \mathrm{Pg} \mathrm{C}$ in wetland vegetation. Furthermore, the carbon sink was estimated as $0.14-0.18 \mathrm{Pg} \mathrm{C} \mathrm{yr}^{-1}$, with an average of $0.16 \mathrm{Pg} \mathrm{C}$ $\mathrm{yr}^{-1}$ (Yu et al., 2013c). With the development of forests, Chinese forests have a huge potential to sequestrate $C$ from atmosphere (Liu et al., 2014), because most forests were young forest and forest age was averaged as 29 years. Under the scenarios of mature forests and with constant forest area, the $\mathrm{C}$ sequestration potential for vegetation and soil were 10.81 and 5.01 Pg C in Chinese forests, respectively (Wen et al., 2016).

\subsubsection{Carbon budget in Chinese terrestrial ecosystem based on biogeographical statistics}

Based on the understanding about the influences of annual mean air temperature and annual precipitation on the spatial variations of GPP, RE, NEP, and soil respiration (RS) (Yu et al., 2013b), researchers developed the approaches of biogeographical statistics on the $\mathrm{C}$ fluxes in China to quantify their magnitudes and spatial distributions (Yu et al., 2010; Zhu et al., 
2014). The results showed that Chinese climate-potential GPP, NEP, RE, and RS in the $2000 \mathrm{~s}$ were $7.78,1.71,6.05$, and $3.96 \mathrm{Pg} \mathrm{C} \mathrm{yr}^{-1}$, respectively, which accounted for $4.45 \%-7.04 \%, 8.14 \%-11.40 \%, 5.87 \%-6.30 \%$, and $4.93 \%$ of the global corresponding fluxes (Yu et al., 2010; Zhu et al., 2014). Furthermore, the whole China was considered as a regional biome-society system to assess its $\mathrm{C}$ sink on the basis of multi-source data integration (Zhu et al., 2014; Wang et al., 2015). The results demonstrated that $\mathrm{C}$ sink in China was about $0.41 \pm 0.12 \mathrm{Pg} \mathrm{C} \mathrm{yr}^{-1}$ (Wang et al., 2015). It is necessary to say that the $\mathrm{C}$ emission resulting from human disturbance can consumed 42.65\% NEP in China (Wang et al., 2015). Therefore, further study should emphasize the importance of reasonable ecosystem management, which may reduce the $\mathrm{C}$ emissions by human activities and lengthen the residence time for the fixed $\mathrm{C}$ in ecosystems (Wang et al., 2015).

\section{Prospect and emphases of ChinaFLUX coordinated observation on ter- restrial ecosystem carbon, nitrogen and water fluxes}

Through ten years development, ChinaFLUX innovatively established the terrestrial ecosystem carbon, nitrogen and water fluxes coordinated observation system, and made important progress in flux observation technology development, ecosystem carbon, nitrogen, water exchange processes and environment control mechanism research, model simulation, and regional carbon, nitrogen and water budget assessment. As entering the new big science and big data era, ChinaFLUX will face more challenges from many aspects of science and technology.

The future major missions of terrestrial ecosystem carbon, nitrogen, water fluxes coordinated observation and research of ChinaFLUX include: (1) achieve $\mathrm{CO}_{2}, \mathrm{H}_{2} \mathrm{O}, \mathrm{CH}_{4}, \mathrm{CO}_{2}$, $\mathrm{NO}, \mathrm{NO}_{2}, \mathrm{~N}_{2} \mathrm{O}, \mathrm{NH}_{3}$ and $\mathrm{HNO}_{3}$ multiple types of carbon, nitrogen, water trace gas fluxes integrated observation, so as to improve and upgrade the technical level of multiple trace greenhouse gas fluxes observation; (2) effectively organize the network observation and improve the spatial representativeness of observational sites, so as to provide services for ecosystem and global change science research; (3) develop the ground-based and space-based integrated observation system, so as to better evaluate the ecosystem carbon source / sinks and environmental response; (4) meet the data requirements of the large-scale, quantitative, predictable and early warning ecological research in the new era. Future ecological research in China are expected to be based on ChinaFLUX, to realize the leap from the ecological factors observation to the whole ecosystem observation, to develop ecological observation satellites, to improve and optimize ecosystem model system, so as to provide better services to the quantitative assessment, scientific prediction, scenario forecast and ecological early warning for the global sustainable development.

\section{References}

Baldocchi D D, 2014. Measuring fluxes of trace gases and energy between ecosystems and the atmosphere: The state and future of the eddy covariance method. Global Change Biology, 20(12): 3600-3609.

Baldocchi D, 2008. Breathing of the terrestrial biosphere: Lessons learned from a global network of carbon dioxide flux measurement systems. Australian Journal of Botany, 56: 1-26.

Cao M K, Yu G R, Liu J Y et al., 2005. Multi-scale observation and cross-scale mechanistic modeling on terres- 
trial ecosystem carbon cycle. Science in China Series D, 48(S1): 17-32.

Chen D X, 2010. Dynamics and controls of carbon exchange of a tropical montane rain forest at Jianfengling, China [D]. Beijing: Chinese Academy of Forestry. (in Chinese)

Chen Z, Yu G R, Ge J P et al., 2013. Temperature and precipitation control of the spatial variation of terrestrial ecosystem carbon exchange in the Asian region. Agricultural and Forest Meteorology, 182: 266-276.

Chen Z, Yu G R, Ge J P et al., 2015a. Roles of climate, vegetation and soil in regulating the spatial variability in ecosystem carbon dioxide fluxes in the Northern Hemisphere. PLoS One, 10(4): e0125265.

Chen Z, Yu G R, Zhu X J et al., 2015b. Covariation between gross primary production and ecosystem respiration across space and the underlying mechanisms: A global synthesis. Agricultural and Forest Meteorology, 203: $180-190$.

Cui S, 2007. Study on the $\mathrm{CO}_{2}$ flux of a larch plantation in NE China by the micrometeorological method [D]. Harbin: Northeast Forestry University. (in Chinese)

Doherty S, Bojinski S, Henderson-Sellers A et al., 2009. Lessons learned from IPCC AR4: Scientific developments needed to understand, predict, and respond to climate change. Bulletin of the American Meteorological Society, 90(4): 497-513.

Doney S C, Mahowald N, Lima I et al., 2007. Impact of anthropogenic atmospheric nitrogen and sulfur deposition on ocean acidification and the inorganic carbon system. Proceedings of the National Academy of Sciences of the United States of America, 104(37): 14580-14585.

Dong G, 2011b. Carbon and water fluxes and water use efficiency of the Songnen meadow steppe in Northeast China [D]. Changchun: Northeast Normal University. (in Chinese)

Dong G, Guo J, Chen J et al., 2011a. Effects of spring drought on carbon sequestration, evapotranspiration and water use efficiency in the Songnen meadow steppe in Northeast China. Ecohydrology, 4(2): 211-224.

Du Q, Liu H Z, Feng J W et al., 2012. Carbon dioxide exchange processes over the grassland ecosystems in semiarid areas of China. Science in China Series D, 42(5): 711-722.

Fan Y Z, Zhang X Z, Wang J S et al., 2009. Effect of solar radiation on net ecosystem $\mathrm{CO}_{2}$ exchange of alpine meadow on the Tibetan Plateau. Journal of Geographical Sciences, 21(4): 666-676.

Fang H J, Cheng S L, Yu G R et al., 2012. Responses of $\mathrm{CO}_{2}$ efflux from an alpine meadow soil on the Qinghai-Tibetan Plateau to multi-form and low-level N addition. Plant and Soil, 351: 177-190.

Fang H J, Cheng S L, Yu G R et al., 2014a. Low-level nitrogen deposition significantly inhibits methane uptake from an alpine meadow soil on the Qinghai-Tibetan Plateau. Geoderma, 213: 444-452.

Fang H J, Cheng S L, Yu G R et al., 2014b. Nitrogen deposition impacts on the amount and stability of soil organic matter in an alpine meadow ecosystem depend on the form and rate of applied nitrogen. European Journal of Soil Science, 65(4): 510-519.

Fang X R, 2011. Carbon exchange and its response to environmental factors in Poplar plantation ecosystem [D]. Beijing: Beijing Forestry University. (in Chinese)

FLUXNET Web Page. 2013. Available online [http://fluxnet.ornl.gov] from Oak Ridge National Laboratory Distributed Active Archive Center (ORNL DAAC), Oak Ridge, Tennessee, USA.

$\mathrm{Fu}$ Y L, Yu G R, Sun X M et al., 2006. Depression of net ecosystem $\mathrm{CO}_{2}$ exchange in semi-arid Leymus chinensis steppe and alpine shrub. Agricultural and Forest Meteorology, 137: 234-244.

Fu Y L, Zheng Z M, Yu G R et al., 2009. Environmental influences on carbon dioxide fluxes over three grassland ecosystems in China. Biogeosciences, 6: 2879-2893.

Gao Y N, Yu G R, Li S G et al., 2015. A remote sensing model to estimate ecosystem respiration in Northern China and the Tibetan Plateau. Ecological Modelling, 304: 34-43.

Gao Y N, Yu G R, Yan H M et al., 2014. A MODIS-based Photosynthetic Capacity Model to estimate gross primary production in northern China and the Tibetan Plateau. Remote Sensing of Environment, 148: 108-118.

Gao Y N, Yu G R, Zhang L et al., 2012. The changes of net primary productivity in Chinese terrestrial ecosystem: Based on process and parameter models. Progress in Geography, 31(1): 109-117. (in Chinese)

Gao Y, He N P, Yu G R et al., 2015. Impact of external nitrogen and phosphorus input between 2006 and 2010 on carbon cycle in China seas. Regional Environmental Change, 15: 631-641. 
Gao Y, Yu G R, He N P, 2013. Equilibration of the terrestrial water, nitrogen, and carbon cycles: Advocating a health threshold for carbon storage. Ecological Engineering, 57: 366-374.

Gao Y, Zhu X J, Yu G R et al., 2014. Water use efficiency threshold for terrestrial ecosystem carbon sequestration in China under afforestation. Agricultural and Forest Meteorology, 195/196: 32-37.

Geng S, 2011. Study on the carbon flux observation over poplar plantation ecosystem of Xiping city in Henan Province of China [D]. Beijing: Beijing Forestry University. (in Chinese)

Gu F X, Tao B, Wen X F et al., 2010. Modeling long-term changes in carbon fluxes and storage in a subtropical coniferous plantation based on CEVSA2 model. Acta Ecologica Sinica, 30(23): 6598-6605. (in Chinese)

Gu F X, Zhang Y, Huang M et al., 2015. Nitrogen deposition and its effect on carbon storage in Chinese forests during 1981-2010. Atmospheric Environment, 123: 171-179.

Guan D X, Wu J B, Zhao X S et al., 2006. $\mathrm{CO}_{2}$ flux over an old, temperate mixed forest in Northeastern China. Agricultural and Forest Meteorology, 137: 138-149.

Guo H Q, 2010. Carbon fluxes over an estuarine wetland: In situ measurement and modeling [D]. Shanghai: Fudan University. (in Chinese)

Han S, 2008. Productivity estimation of the poplar plantations on the beaches in middle and low reaches of Yangtze River using eddy covariance measurement [D]. Beijing: Chinese Academy of Forestry. (in Chinese)

Hao Y B, Kang X M, Wu X et al., 2013. Is frequency or amount of precipitation more important in controlling $\mathrm{CO}_{2}$ fluxes in the 30-year-old fenced and the moderately grazed temperate steppe? Agriculture, Ecosystems and Environment, 171(1): 63-71.

Hao Y B, Niu H S, Wang Y F et al., 2011. Rainfall variability in ecosystem $\mathrm{CO}_{2}$ fluxes studies. Climate Research, 46: 77-83.

Hao Y B, Wang Y F, Cui X Y, 2010a. Drought stress reduces the carbon accumulation of the Leymus chinensis steppe in Inner Mongolia, China. Journal of Plant Ecology, 34: 898-906. (in Chinese)

Hao Y B, Wang Y F, Mei X R et al., 2010b. The response of ecosystem $\mathrm{CO}_{2}$ exchange to small precipitation pulses over a temperate steppe. Plant Ecology, 209(2): 335-347.

He H L, Liu M, Sun X M et al., 2010. Uncertainty analysis of eddy flux measurements in typical ecosystems of ChinaFLUX. Ecological Informatics, 5(6): 492-502.

He H L, Liu M, Xiao X M et al., 2014. Large-scale estimation and uncertainty analysis of gross primary production in Tibetan alpine grasslands. Journal of Geophysical Research, 119(3): 466-486.

Hu Z M, Li S G, Yu G R, 2013. Modeling evapotranspiration by combining a two-source model, a leaf stomatal model, and a light-use efficiency model. Journal of Hydrology, 501: 186-192.

$\mathrm{Hu}$ Z M, Wen X F, Sun X M et al., 2014. Partitioning of evapotranspiration through oxygen isotopic measurements of water pools and fluxes in a temperate grassland. Journal of Geophysical Research: Biogeosciences, 119: 2013JG002367.

Hu Z M, Yu G R, Fu Y L et al., 2008. Effects of vegetation control on ecosystem water use efficiency within and among four grassland ecosystems in China. Global Change Biology, 14(7): 1609-1619.

Hu Z M, Yu G R, Zhou Y L et al., 2009. Partitioning of evapotranspiration and its controls in four grassland ecosystems: Application of a two-source model. Agricultural and Forest Meteorology, 149: 1410-1420.

Huang H, Zhang J S, Meng P et al., 2011. Seasonal variation and meteorological control of $\mathrm{CO}_{2}$ flux in a hilly plantation in the mountain areas of North China. Acta Meteorologica Sinica, 25(2): 238-248. (in Chinese)

Huang L J, Wen X F, 2014. Temporal variations of atmospheric water vapor delta D and delta O-18 above an arid artificial oasis cropland in the Heihe River Basin. Journal of Geophysical Research-Atmospheres, 119: 11456-11476.

Huang M, Ji J J, Deng F et al., 2014. Impacts of extreme precipitation on tree plantation carbon cycle. Theoretical and Applied Climatology, 115(3/4): 655-665.

Ji J J, Huang M, Li K R, 2008. Prediction of carbon exchanges between China terrestrial ecosystem and atmosphere in 21st century. Science in China Series D, 51(6): 885-898.

Jia B R, Zhou G S, Jiang Y L et al., 2013. Temporal-spatial characteristics of soil respiration in Chinese boreal forest ecosystem. Acta Ecologica Sinica, 33(23): 7516-7524. (in Chinese) 
Jia Y L, Yu G R, Gao Y N et al., 2016. Global inorganic nitrogen dry deposition inferred from ground- and space-based measurements. Scientific Reports, 6: 19810.

Jia Y L, Yu G R, He N P et al., 2014. Spatial and decadal variations in inorganic nitrogen wet deposition in China induced by human activity. Scientific Reports, 4: 3763.

Jiang C M, Yu G R, Fang H J et al., 2010. Short-term effect of increasing nitrogen deposition on $\mathrm{CO}_{2}, \mathrm{CH}_{4}$ and $\mathrm{N}_{2} \mathrm{O}$ fluxes in an alpine meadow on the Qinghai-Tibetan Plateau, China. Atmospheric Environment, 44: 2920-2926.

Ju W M, Wang S Q, Yu G R et al., 2010. Modeling the impact of drought on canopy carbon and water fluxes for a subtropical evergreen coniferous plantation in southern China through parameter optimization using an ensemble Kalman filter. Biogeosciences, 7: 845-857.

Kato T, Tang Y H, Gu S et al., 2006. Temperature and biomass influences on interannual changes in $\mathrm{CO}_{2}$ exchange in an alpine meadow on the Qinghai-Tibetan Plateau. Global Change Biology, 12: 1285-1298.

Le Quéré C, Andres R J, Boden T et al., 2013. The global carbon budget 1959-2011. Earth System Science Data, 5: 165-185.

Lei H M, Yang D W, 2010a. Seasonal and interannual variations in carbon dioxide exchange over a cropland in the North China Plain. Global Change Biology, 16(11): 2944-2957.

Lei H M, Yang D W, 2010b. Interannual and seasonal variability in evapotranspiration and energy partitioning over an irrigated cropland in the North China Plain. Agricultural and Forest Meteorology, 150(4): 581-589.

Lei H, Yang D, 2010. Seasonal and interannual variations in carbon dioxide exchange over a cropland in the North China Plain. Global Change Biology, 16: 2944-2957.

Leuning R, Yu G R, 2006. Carbon exchange research in ChinaFLUX. Agricultural and Forest Meteorology, 137: $123-124$.

Li X, Liang S, Yuan W et al., 2014. Estimation of evapotranspiration over the terrestrial ecosystems in China. Ecohydrology, 7: 139-149.

Li X, Sun R, Li Y et al., 2010. Carbon dioxide fluxes on green space in Haidian park, Beijing. Acta Ecologica Sinica, 30: 6715-6725. (in Chinese)

Li X Y, Cheng S L, Fang H J et al., 2015. The contrasting effects of deposited $\mathrm{NH}_{4}{ }^{+}$and $\mathrm{NO}_{3}{ }^{-}$on soil $\mathrm{CO}_{2}, \mathrm{CH}_{4}$ and $\mathrm{N}_{2} \mathrm{O}$ fluxes in a subtropical plantation, southern China. Ecological Engineering, 85: 317-327.

Li Y N, Sun X M, Zhao X Q et al., 2006. Seasonal variations and mechanism for environmental control of NEE of $\mathrm{CO}_{2}$ concerning the Potentilla Fruticosa in alpine shrub meadow of Qinghai-Tibet Plateau. Science in China Series D, 49(S2): 174-185.

Li Z, Zhang Y, Wang S et al., 2010. Evapotranspiration of a tropical rain forest in Xishuangbanna, Southwest China. Hydrological Processes, 24: 2405-2416.

Li Z Q, Yu G R, Xiao X M et al., 2007. Modeling gross primary production of alpine ecosystems in the Tibetan Plateau using MODIS images and climate data. Remote Sensing of Environment, 107(3): 510-519.

Liu L L, Greaver T L, 2010. A global perspective on belowground carbon dynamics under nitrogen enrichment. Ecological Letters, 13(7): 819-828.

Liu M, He H L, Ren X L et al., 2015. The effects of constraining variables on parameter optimization in carbon and water flux modeling over different forest ecosystems. Ecological Modelling, 303: 30-41.

Liu M, He H L, Yu G R et al., 2009. Uncertainty analysis of $\mathrm{CO}_{2}$ flux components in subtropical evergreen coniferous plantation. Science in China Series D, 52: 257-268.

Liu M, He H L, Yu G R et al., 2012. Uncertainty analysis in data processing on the estimation of net carbon exchanges at different forest ecosystems in China. Journal of Forest Research, 17(3): 312-322.

Liu R, Li Y, Wang Q X, 2011b. Variations in water and $\mathrm{CO}_{2}$ fluxes over a saline desert in western China. Hydrological Processes, 26(4): 513-522.

Liu R, Li Y, Wang Q X et al., 2011a. Seasonal and annual variations of carbon dioxide fluxes in desert ecosystem. Journal of Desert Research, 31(1): 108-114. (in Chinese)

Liu Y C, Yu G R, Wang Q F et al., 2014. Carbon carry capacity and carbon sequestration potential in China based on an integrated analysis of mature forest biomass. Science China: Life Sciences, 57(12): 1218-1229. 
Liu Y F, Yu G R, Wen X F et al., 2006. Seasonal dynamics of $\mathrm{CO}_{2}$ fluxes from subtropical plantation coniferous ecosystem. Science in China Series D, 49(S2): 99-109.

Liu Z, Guan D B, Wei W et al., 2015. Reduced carbon emission estimates from fossil fuel combustion and cement production in China. Nature, 524 (7565): 335-338.

Luyssaert S, Inglima I, Jung $\mathrm{M}$ et al., 2007. $\mathrm{CO}_{2}$ balance of boreal, temperate, and tropical forests derived from a global database. Global Change Biology, 13: 2509-2537.

Mi N, Yu G R, Wang P X et al., 2007. Modeling seasonal variation of $\mathrm{CO}_{2}$ flux in a subtropical coniferous forest using the EALCO model. Journal of Plant Ecology, 31(6): 1119-1131. (in Chinese)

Mi N, Yu G R, Wen X F et al., 2009. Use of ecosystem flux data and a simulation model to examine seasonal drought effects on a subtropical coniferous forest. Asia-Pacific Journal of Atmospheric Sciences, 45(2): 207-220.

Pang J P, Wen X F, Sun X M, 2016. Mixing ratio and carbon isotopic composition investigation of atmospheric $\mathrm{CO}_{2}$ in Beijing, China. Science of the Total Environment, 539: 322-330.

Qiu L, Zu Y G, Wang W J et al., 2011. $\mathrm{CO}_{2}$ flux characteristics and their influence on the carbon budget of a larch plantation in Maoershan region of Northeast China. Chinese Journal of Applied Ecology, 22(1): 1-8. (in Chinese)

Reichstein M, Bahn M, Mahecha M D et al., 2014. Linking plant and ecosystem functional biogeography. Proceedings of the National Academy of Sciences of the United States of America, 111: 13697-13702.

Ren C Y, Yu G R, Wang Q F et al., 2005. Photosynthesis-transpiration coupling model at canopy scale in terrestrial ecosystem. Science in China Series D, 48(S1): 160-171.

Ren X L, He H L, Liu M et al., 2012. Modeling of carbon and water fluxes of Qianyanzhou subtropical coniferous plantation using model-data fusion approach. Acta Ecologica Sinica, 32(23): 7313-7326. (in Chinese)

Saigusa N, Li S G, Kwon $\mathrm{H}$ et al., 2013. Dataset of CarboEastAsia and uncertainties in the $\mathrm{CO}_{2}$ budget evaluation caused by different data processing. Journal of Forest Research, 18(1): 41-48.

Sheng W P, Yu G R, Fang H J et al., 2010. Observation methods for atmospheric nitrogen deposition. Chinese Journal of Ecology, 29(8): 1671-1678. (in Chinese)

Sheng W P, Yu G R, Fang H J et al., 2014. Regional pattern of ${ }^{15} \mathrm{~N}$ natural abundance in the forest ecosystems along a large transect in eastern China. Scientific Reports. DOI: 10.1038/srep04249.

Sheng W P, Yu G R, Jiang C M et al., 2012. Monitoring nitrogen deposition in typical forest ecosystems along a large transect in China. Environmental Monitoring and Assessment, 185: 833-844.

Shi P L, Sun X M, Xu L L et al., 2006. Net ecosystem $\mathrm{CO}_{2}$ exchange and controlling factors in a steppe: Kobresia meadow on the Tibetan Plateau. Science in China Series D, 49(S2): 207-218.

Song Q H, Tan Z H, Zhang Y P et al., 2013. Spatial heterogeneity of soil respiration in a seasonal rainforest with complex terrain. iForest - Biogeosciences and Forestry, 6: 65-72.

Song T, 2007. Long term carbon dioxide flux measurements in Sanjiang Plain, Northeastern China [D]. Nanjing: Nanjing University of Information Science and Technology. (in Chinese)

Stoy P, Mauder M, Foken T et al., 2013. A data-driven analysis of energy balance closure across FLUXNET research sites: The role of landscape scale heterogeneity. Agricultural and Forest Meteorology, 171: 137-152.

Sun J T, 2012. Study of $\mathrm{CO}_{2}$ flux above urban green space in Perl River Delta [D]. Nanjing: Nanjing University of Information Science and Technology. (in Chinese)

Tan Z H, Zhang Y P, Liang N S et al., 2012. An observational study of the carbon-sink strength of East Asian subtropical evergreen forests. Environmental Research Letters, 7. doi: 10.1088/1748-9326/7/4/044017.

Tan Z H, Zhang Y P, Liang N S et al., 2013. Soil respiration in an old-growth subtropical forest: Patterns, components, and controls. Journal of Geophysical Research-Atmospheres, 118(7): 2981-2990.

Tan Z H, Zhang Y P, Schaefer D et al., 2011. An old-growth subtropical Asian evergreen forest as a large carbon sink. Atmospheric Environment, 45: 1548-1554.

Tan Z H, Zhang Y P, Yu G R et al., 2010. Carbon balance of a primary tropical seasonal rain forest. Journal of Geophysical Research, 115: D00H26.

Tang Y K, Wen X F, Sun X M et al., 2014. The limiting effect of deep soil water on evapotranspiration of a sub- 
tropical coniferous plantation subjected to seasonal drought. Advances in Atmospheric Sciences, 31: $385-395$.

The Ministry of Water Resources of the People's Republic of China (MWR), 2011a. Chinese River and Sediment Bulletin, 2000-2011. (in Chinese)

The Ministry of Water Resources of the People's Republic of China (MWR), 2011b. Chinese Water Conservancy Yearbook. (in Chinese)

Tong X, Zhang J, Meng P et al., 2010. Characteristics of net carbon exchange over a mixed plantation in a hilly area of the north China. Scientia Silvae Sinicae, 46: 37-43. (in Chinese)

Wang B, Li J, Jiang W W et al., 2012. Impacts of the rangeland degradation on $\mathrm{CO}_{2}$ flux and the underlying mechanisms in the Three-River Source Region on the Qinghai-Tibetan Plateau. China Environmental Science, 32(10): 1764-1771. (in Chinese)

Wang H M, Saigusa N, Zu Y G et al., 2008. Carbon fluxes and their response to environmental variables in a Dahurian larch forest ecosystem in Northeast China. Journal of Forestry Research, 19(1): 1-10.

Wang K, Dickinson R E, 2012. A review of global terrestrial evapotranspiration: Observation, modeling, climatology, and climatic variability. Reviews of Geophysics, 50: RG2005.

Wang Q F, Niu D, Yu G R et al., 2005. Simulating the exchanges of carbon dioxide, water vapor and heat over Changbai Mountains temperate broad-leaved Korean pine mixed forest ecosystem. Science in China Series D, 48(S1): 148-159.

Wang Q F, Zheng H, Zhu X J et al., 2015. Primary estimation of Chinese terrestrial carbon sequestration during 2001-2010. Science Bulletin, 60(6): 577-590.

Wang S M, Hu J C, Wu G X et al., 2011. Characteristic analysis of $\mathrm{CO}_{2}$ fluxes from a rice paddy ecosystem in a subtropical region. Acta Scientiae Circumstantiae, 31: 217-224. (in Chinese)

Wang S Q, Chen J M, Ju W M et al., 2007. Carbon sinks and sources in China's forests during 1901-2001. Journal of Environmental Management, 85(3): 524-537.

Wang Y F, Cui X Y, Hao Y B et al., 2011. The fluxes of $\mathrm{CO}_{2}$ from grazed and fenced temperate steppe during two drought years. Science of the Total Environment, 410/411: 182-190.

Wang Y L, Zhou G S, Wang Y H, 2008b. Environmental effects on net ecosystem $\mathrm{CO}_{2}$ exchange at half-hour and month scales over Stipa krylovii steppe in northern China. Agricultural and Forest Meteorology, 148(5): 714-722.

Wang Y S, Cheng S L, Fang H J et al., 2014. Simulated nitrogen deposition reduces $\mathrm{C}_{\mathrm{H} 4}$ uptake and increases $\mathrm{N}_{2} \mathrm{O}$ emission from a subtropical plantation forest soil in southern China. PloS One, 9(4): e93571.

Wang Y S, Cheng S L, Fang $\mathrm{H}$ J et al., 2015. Contrasting effects of ammonium and nitrate inputs on soil $\mathrm{CO}_{2}$ emission in a subtropical coniferous plantation of southern China. Biology and Fertility of Soils, 51: 815-825.

Wang Y S, Cheng S L, Fang H J et al., 2016. Significant regulations of ammonia-oxidizing communities to methane uptake and nitrous oxide emission from the subtropical plantation soil under nitrogen enrichment. European Journal of Soil Biology. (accepted)

Wang Y, Zhou G S, Jia B R et al., 2010a. Comparisons of carbon flux and its controls between broad-leaved Korean pine forest and Dahurian larch forest in northeast China. Acta Ecologica Sinica, 30: 4376-4388. (in Chinese)

Wang Z, Xiao X M, Yan X D, 2010b. Modeling gross primary production of maize cropland and degraded grassland in northeastern China. Agricultural and Forest Meteorology, 150: 1160-1167.

Wen D, He N P, 2016. Spatial patterns and control mechanisms of carbon storage in forest ecosystem: Evidence from the north-south transect of eastern China. Ecological Indicator. doi: 10.1016/j.ecolind.2015.10.054.

Wen X F, Lee X H, Sun X M et al., 2012. Dew water isotopic ratios and their relationships to ecosystem water pools and fluxes in a cropland and a grassland in China. Oecologia, 168: 549-561.

Wen X F, Sun X M, Zhang S C et al., 2008. Continuous measurement of water vapor D/H and ${ }^{18} \mathrm{O} /{ }^{16} \mathrm{O}$ isotope ratios in the atmosphere. Journal of Hydrology, 349: 489-500.

Wen X F, Yu G R, Sun X M et al., 2006. Soil moisture effects on the temperature dependence of ecosystem respiration in a subtropical Pinus plantation of southeastern China. Agricultural and Forest Meteorology, 137: $166-175$. 
Wen X F, Zhang S C, Sun X M et al., 2010. Water vapor and precipitation isotope ratios under the influence of the Asian monsoon climate. Journal of Geophysical Research-Atmospheres, 115. doi: 10.1029/2009JD012408.

$\mathrm{Wu} \mathrm{L}, \mathrm{Gu} \mathrm{S}$, Zhao L et al., 2010. Variation in net $\mathrm{CO}_{2}$ exchange, gross primary production and its affecting factors in the planted pasture ecosystem in Sanjiangyuan Region of the Qinghai-Tibetan Plateau of China. Acta Phytoecologica Sinica, 34: 770-780. (in Chinese)

$\mathrm{Wu} \mathrm{L} \mathrm{B,} \mathrm{Gu} \mathrm{S,} \mathrm{Zhao} \mathrm{L} \mathrm{et} \mathrm{al.,} \mathrm{2010.} \mathrm{Variation} \mathrm{in} \mathrm{net} \mathrm{CO}_{2}$ exchange, gross primary production and its affecting factors in the planted pasture ecosystem in Sanjiangyuan Region of the Qinghai-Tibetan Plateau of China. Chinese Journal of Plant Ecology, 34(7): 770-780. (in Chinese)

Wu W X, Wang S Q, Xiao X M et al., 2008. Modeling gross primary production of a temperate grassland ecosystem in Inner Mongolia, China, using MODIS imagery and climate data. Science in China Series D, 51(10): 1501-1512.

Xu M J, Wen X F, Wang H M et al., 2014. Effects of climatic factors and ecosystem responses on the inter-annual variability of evapotranspiration in a coniferous plantation in subtropical China. PLoS One, 9: e85593.

$\mathrm{Xu}$ X, Li Q, Wang J et al., 2014. Inorganic and organic nitrogen acquisition by a fern dicranopteris dichotoma in a subtropical forest in South China. PLoS One, 9(5): e90075.

Yan J H, Liu X Z, Tang X L et al., 2012. Substantial amounts of carbon are sequestered during dry periods in an old-growth subtropical forest in South China. Journal of Forest Research. doi: 10.1007/s10310-012-0363-0.

Yan J H, Zhang Y P, Yu G R et al., 2013. Seasonal and inter-annual variations in net ecosystem exchange of two old-growth forests in southern China. Agricultural and Forest Meteorology, 182(SI): 257-265.

Yan L M, Chen S P, Huang J et al., 2011b. Water regulated effects of photosynthetic substrate supply on soil respiration in a semiarid steppe. Global Change Biology, 17: 1990-2001.

Yan Y E, 2009. Carbon flux in an estuarine wetland estimated by remote model and ground-based observations [D]. Shanghai: Fudan University. (in Chinese)

Yang F L, Zhou G S, Hunt J E et al., 2011. Biophysical regulation of net ecosystem carbon dioxide exchange over a temperate desert steppe in Inner Mongolia, China. Agriculture Ecosystems and Environment, 142: 318-328.

Yao Y G, Zhang Y P, Liang N S et al., 2012. Pooling of $\mathrm{CO}_{2}$ within a small valley in a tropical seasonal rain forest. Journal of Forest Research, 17: 241-252.

Yu C L, Liu D, 2011. Analysis on $\mathrm{CO}_{2}$ flux during growth season of natural broadleaved mixed forest in Xiaoxinganling Mountains. Chinese Journal of Agrometeorology, 32: 525-529. (in Chinese)

Yu G R, Chen Z, Piao S L et al., 2014c. High carbon dioxide uptake by subtropical forest ecosystems in the East Asian monsoon region. Proceedings of the National Academy of Sciences of the United States of America, 111: 4910-4915.

Yu G R, Fu Y L, Sun X M et al., 2006a. Recent progress and future directions of ChinaFLUX. Science in China Series D, 36(S1): 1-21.

Yu G R, Gao Y, Wang Q F et al., 2013a. Discussion on the key processes of carbon-nitrogen-water coupling cycles and biological regulation mechanisms in terrestrial ecosystem. Chinese Journal of Eco-Agriculture, 21(1): 1-13. (in Chinese)

Yu G R, He N P, Wang Q F, 2013c. Carbon Budget and Carbon Sink of Ecosystems in China: Theoretical Basis and Comprehensive Assessment. Beijing: Science Press. (in Chinese)

Yu G R, Song X, Wang Q F et al., 2008. Water-use efficiency of forest ecosystems in eastern China and its relations to climatic variables. New Phytologist, 177(4): 927-937.

Yu G R, Sun X M, 2006. Principles of Flux Measurement in Terrestrial Ecosystems. Beijing: Higher Education Press: 1-508. (in Chinese)

Yu G R, Sun X M. 2008. Flux Measurement and Research of Terrestrial Ecosystem in China. Beijing: Science Press: 1-676. (in Chinese)

Yu G R, Wang Q F, Fang H J, 2014b. Fundamental scientific issues, theoretical framework and relative research methods of carbon-nitrogen-water coupling cycles in terrestrial ecosystems. Quaternary Sciences, 34(4): 683-698. (in Chinese)

Yu G R, Wen X F, Li Q K et al., 2005. Seasonal patterns and environmental control of ecosystem respiration in 
subtropical and temperate forest in China. Science in China Series D, 48(S1): 93-105.

Yu G R, Wen X F, Sun X M et al., 2006b. Overview of ChinaFLUX and evaluation of its eddy covariance measurement. Agricultural and Forest Meteorology, 137: 125-137.

Yu G R, Zhang L M, Sun X M et al., 2008. Environmental controls over carbon exchange of three forest ecosystems in eastern China. Global Change Biology, 14(11): 2555-2571.

Yu G R, Zhang L M, Sun X M. 2014a. Progresses and prospects of Chinese terrestrial ecosystem flux observation and research network (ChinaFLUX). Progress in Geography, 33(7): 903-917. (in Chinese)

Yu G R, Zheng Z M, Wang Q F et al., 2010. Spatiotemporal pattern of soil respiration of terrestrial ecosystems in China: The development of a geostatistical model and its simulation. Environmental Science and Technology, 44: 6074-6080.

Yu G R, Zhu X J, Fu Y L et al., 2013b. Spatial patterns and climate drivers of carbon fluxes in terrestrial ecosystems of China. Global Change Biology, 19(3): 798-810.

Yuan W P, Liu S G, Yu G R, 2010. Global estimates of evapotranspiration and gross primary production based on MODIS and global meteorology data. Remote Sensing of Environment, 114: 1416-1431.

Zha T G, 2007. Carbon balance of a poplar plantation ecosystem in Daxing [D]. Beijing: Beijing Forestry University. (in Chinese)

Zhan X Y, Yu G R, He N P et al., 2014. Nitrogen deposition and its spatial pattern in main forest ecosystems along north-south transect of eastern China. Chinese Geographical Science, 24(2): 137-146.

Zhan X Y, Yu G R, He N P et al., 2015. Inorganic nitrogen wet deposition: Evidence from the North-South Transect of Eastern China. Environmental Pollution, 204: 1-8.

Zhang J H, Han S J, Yu G R, 2006a. Seasonal variation in carbon dioxide exchange over a 200-year-old Chinese broad-leaved Korean pine mixed forest. Agricultural and Forest Meteorology, 137: 150-165.

Zhang L, Luo Y Q, Yu G Q et al., 2010. Estimated carbon residence times in three forest ecosystems of Eastern China: Applications of probabilistic inversion. Journal of Geophysical Research-Biogeosciences, 115: G01010.

Zhang L M, Yu G R, Sun X M et al., 2006b. Seasonal variation of carbon exchange of typical forest ecosystems along the eastern forest transect in China. Science in China Series D, 49(S2): 47-62.

Zhang L M, Yu G R, Sun X M et al., 2006c. Seasonal variations of ecosystem apparent quantum yield $(\alpha)$ and maximum photosynthesis rate $\left(P_{\max }\right)$ of different forest ecosystems in China. Agricultural and Forest Meteorology, 137: 176-187.

Zhang L P, 2010. Characteristics of $\mathrm{CO}_{2}$ flux in a Chinese Fir plantations ecosystem in Huitong County, Human Province [D]. Changsha: Central South University of Forestry and Technology. (in Chinese)

Zhang L, Yu G R, Luo Y Q et al., 2009. Carbon cycle modeling of a broad-leaved Korean pine forest in Changbai Mountain of China using the model-data fusion approach. Chinese Journal of Plant Ecology, 33(6): 1044-1055. (in Chinese)

Zhang M, Yu G R, Zhang L M et al., 2010. Impact of cloudiness on net ecosystem exchange of carbon dioxide in different types of forest ecosystems in China. Biogeosciences, 7: 711-722.

Zhang M, Yu G R, Zhang L M et al., 2009. Effects of solar radiation on net ecosystem exchange of broadleaved-Korean pine mixed forest in Changbai Mountain, China. Chinese Journal of Plant Ecology, 33(2): 270-282. (in Chinese)

Zhang M, Yu G R, Zhuang J et al., 2011. Effects of cloudiness change on net ecosystem exchange, light use efficiency, and water use efficiency in typical ecosystems of China. Agricultural and Forest Meteorology, 151(7): 803-816.

Zhang S C, Sun X M, Wang J L et al., 2011. Short-term variations of vapor isotope ratios reveal the influence of atmospheric processes. Journal of Geographical Sciences, 21: 401-416.

Zhang W L, 2007. Carbon fluxes of typical steppe and cropland ecosystems in the agri-pasture transition region of Inner Mongolia, China [D]. Beijing: Chinese Academy of Sciences. (in Chinese)

Zhang W L, Chen S P, Chen J et al., 2007. Biophysical regulations of carbon fluxes of a steppe and a cultivated cropland in semiarid Inner Mongolia. Agricultural and Forest Meteorology, 146: 216-229. 
Zhang Y P, Tan Z H, Song Q H et al., 2010. Respiration controls the unexpected seasonal pattern of carbon flux in an Asian tropical rain forest. Atmospheric Environment, 44: 3886-3893.

Zhao F H, Yu G R, Li S G et al., 2007. Canopy water use efficiency of winter wheat in the North China Plain. Agricultural Water Management, 93(3): 99-108.

Zhao L, Li Y N, Xu S X et al., 2006. Diurnal, seasonal and annual variation in net ecosystem $\mathrm{CO}_{2}$ exchange of an alpine shrubland on Qinghai-Tibetan Plateau. Global Change Biology, 12(10): 1940-1953.

Zhao Z H, 2011. A study on carbon flux between Chinese fir planations and atmosphere in subtropical belts [D]. Changsha: Central South University of Forestry and Technology. (in Chinese)

Zheng H, Wang Q, Zhu X et al., 2014. Hysteresis responses of evapotranspiration to meteorological factors at a diel timescale: Patterns and causes. PLoS One, 9: e98857.

Zheng H, Yu G, Wang Q et al., 2016. Spatial variation in annual actual evapotranspiration of terrestrial ecosystems in China: Results from eddy covariance measurements. Journal of Geographical Sciences. (Accepted)

Zheng X H, Mei B L, Wang Y H et al., 2008. Quantification of $\mathrm{N}_{2} \mathrm{O}$ fluxes from soil-plant systems may be biased by the applied gas chromatograph methodology. Plant and Soil, 311: 211-234.

Zheng Z M, Yu G R, Sun X M et al., 2010. Spatio-temporal variability of soil respiration of forest ecosystems in China: Influencing factors and evaluation model. Environment Management, 46(4): 633-642.

Zhou G S, Wang Y, Zhou L, 2010. Seasonal Dynamics of Carbon Budget in Typical Maize and Paddy Ecosystem in the Liaohe River Delta of China. Beijing: China Agriculture Press. (in Chinese)

Zhou L Y, Jia B R, Zhou G S et al., 2010. Carbon exchange of Chinese boreal forest during its growth season and related regulation mechanisms. Chinese Journal of Applied Ecology, 21(10): 2449-2456. (in Chinese)

Zhou L, Zhou G, Jia Q, 2009. Annual cycle of $\mathrm{CO}_{2}$ exchange over a reed (Phragmites australis) wetland in Northeast China. Aquatic Botany, 91(2): 91-98.

Zhou L, Zhou G, Liu S et al., 2010. Seasonal contribution and interannual variation of evapotranspiration over a reed marsh (Phragmites australis) in Northeast China from 3-year eddy covariance data. Hydrological Processes, 24(8): 1039-1047.

Zhu J X, He N P, Wang Q F et al., 2015. The composition, spatial patterns, and influencing factors of atmospheric nitrogen deposition in Chinese terrestrial ecosystems. Sciences of Total Environment, 511: 777-785.

Zhu X J, Yu G R, Gao Y N et al., 2012. Fluxes of particulate carbon from rivers to the ocean and their changing tendency in China. Progress in Geography, 31(1): 118-122. (in Chinese)

Zhu X J, Yu G R, He H L et al., 2014a. Geographical statistical assessments of carbon fluxes in terrestrial ecosystems of China: Results from upscaling network observations. Global and Planetary Change, 118: 52-61.

Zhu X J, Yu G R, Wang Q F et al., 2014b. Seasonal dynamics of water use efficiency of typical forest and grassland ecosystems in China. Journal of Forest Research, 19(1): 70-76.

Zhu X J, Yu G R, Wang Q F et al., 2015. Spatial variability of water use efficiency in China's terrestrial ecosystems. Global and Planetary Change, 129: 37-44.

Zhu Y L, 2005. Carbon dioxide exchange between paddy ecosystem and the atmosphere in the subtropical region [D]. Beijing: Chinese Academy of Sciences and Ministry of Education. (in Chinese) 